\title{
Ecology, evolution, and epidemiology of zoonotic and vector-borne infectious diseases in French Guiana: transdisciplinarity does matter to tackle new emerging threats
}

Benoît de Thoisy ${ }^{a}(\mathbb{D})$, Olivier Duron ${ }^{b, c} \neq$, Loïc Epelboin ${ }^{d, \ddagger}$, Lise Musset ${ }^{e \ddagger}$, Philippe Quénel ${ }^{f, \neq}$, Benjamin Roche $^{\mathrm{b}, \mathrm{c} \ddagger}$, Florian Binetruy ${ }^{\mathrm{b}}$, Sébastien Briolant ${ }^{\mathrm{g}, \mathrm{h}, \mathrm{i}}$, Luisiane Carvalho ${ }^{j}$, Agathe Chavy ${ }^{\mathrm{a}}$, Pierre Couppié $^{k}$, Magalie Demar ${ }^{1, m}$, Maylis Douine ${ }^{n}$, Isabelle Dusfour ${ }^{0, p}$, Yanouk Epelboin ${ }^{p}$, Claude Flamand ${ }^{\mathrm{q}, \mathrm{r}}$, Alain Franc ${ }^{s, t}$, Marine Ginouvès ${ }^{1, m}$, Sébastien Gourbière ${ }^{~}$, Emeline Houël ${ }^{v}$, Arthur Kocher ${ }^{w, x}$, Anne Lavergne $^{a}$, Paul Le Turnier ${ }^{\vee}$, Luana Mathieu ${ }^{f}$, Jérôme Murienne ${ }^{x}$, Mathieu Nacher ${ }^{n}$, Stéphane Pelleau ${ }^{\mathrm{f}, \mathrm{z}}$, Ghislaine Prévot ${ }^{1, m}$, Dominique Rousset ${ }^{\text {aa }}$, Emmanuel Roux ${ }^{\mathrm{bb}, \mathrm{cc}}$, Roxane Schaub ${ }^{1, m, n}$, Stanislas Talaga ${ }^{\text {b,p }}$, Pauline Thill ${ }^{\text {dd }}$, Sourakhata Tirera ${ }^{a}$, Jean-François Guégan ${ }^{\text {b,ee }}$ (iD

BdT's ORCID number: orcid.org/0000-0002-8420-5112

JFG's ORCID number: orcid.org/0000-0002-7218-107X

Addresses:

a. Laboratoire des Interactions Virus-Hôtes, Institut Pasteur de la Guyane, Cayenne Cedex, French Guiana.

b. UMR MIVEGEC, IRD, CNRS, Université de Montpellier, Centre IRD de Montpellier, Montpellier, France.

c. Centre de Recherche en Écologie et Évolution de la Santé, Montpellier, France.

d. Infectious Diseases Department, Centre Hospitalier de Cayenne, Cayenne, French Guiana.

e. Laboratoire de parasitologie, Centre Collaborateur OMS pour la surveillance des résistances aux antipaludiques, Centre National de référence du Paludisme, Pôle zones endémiques, Institut Pasteur de la Guyane, Cayenne, French Guiana. 
f. Université de Rennes, Inserm, EHESP, Irset (Institut de recherche en santé, environnement et travail) - UMR-S 1085, Rennes, France.

g. Unité Parasitologie et Entomologie, Département Microbiologie et Maladies Infectieuses, Institut de Recherche Biomédicale des Armées, Marseille, France.

h. Aix Marseille Université, IRD, SSA, AP-HM, UMR Vecteurs - Infections Tropicales et Méditerranéennes (VITROME), France.

i. IHU Méditerranée Infection, Marseille, France.

j. Santé publique France, Cellule Guyane, Saint-Maurice, France.

k. Dermatology Department, Centre Hospitalier de Cayenne, Cayenne, French Guiana.

I. TBIP, Université de Guyane, Cayenne, French Guiana.

m. Université de Lille, CNRS, Inserm, Institut Pasteur de Lille, U1019-UMR 9017-CIIL Centre d'Infection et d'Immunité de Lille, Lille, France.

n. Centre d'Investigation Clinique Antilles-Guyane, Inserm 1424, Centre Hospitalier de Cayenne, Cayenne, French Guiana.

o. Département de Santé Globale, Institut Pasteur, Paris, France.

p. Institut Pasteur de la Guyane, Vectopôle Amazonien Emile Abonnenc, Cayenne, French Guiana.

q. Epidemiology unit, Institut Pasteur de la Guyane, Cayenne, French Guaina.

r. Mathematical Modelling of Infectious Diseases Unit, Institut Pasteur, UMR 2000, CNRS, Paris, France.

s. UMR BIOGECO, INRAE, Université de Bordeaux, Cestas, France.

t. Pleiade, EPC INRIA-INRAE-CNRS, Université de Bordeaux Talence, France. 
u. UMR 5096 Laboratoire Génome et Développement des Plantes, Université de Perpignan Via Domitia, Perpignan, France.

v. CNRS, UMR EcoFoG, AgroParisTech, Cirad, INRAE, Université des Antilles, Université de Guyane, Cayenne, France.

w. Transmission, Infection, Diversification \& Evolution group, Max-Planck Institute for the Science of Human History, Kahlaische Str. 10, 07745 Jena, Germany.

x. Laboratoire Evolution et Diversité Biologique (UMR 5174) - Université de Toulouse, CNRS, IRD, UPS Toulouse, France.

y. Service de Maladies Infectieuses et Tropicales, Hôtel Dieu - INSERM CIC 1413, Centre Hospitalier Universitaire de Nantes, Nantes, France.

z. Malaria : Parasites and Hosts, Institut Pasteur, Paris, France.

aa. Laboratoire de Virologie, Institut Pasteur de la Guyane, Cayenne Cedex, French Guiana.

bb. ESPACE-DEV (Institut de Recherche pour le Développement, Université de la Réunion, Université des Antilles, Université de Guyane, Université de Montpellier), Montpellier, France.

cc. International Joint Laboratory “Sentinela” (Fundação Oswaldo Cruz, Universidade de Brasília, Institut de Recherche pour le Développement), Rio de Janeiro RJ-21040-900, Brazil.

dd. Service Universitaire des Maladies Infectieuses et du Voyageur, Centre Hospitalier Dron, Tourcoing, France.

ee. UMR ASTRE, INRAE, CIRAD, Université de Montpellier, Montpellier, France.

${ }^{\ddagger}$ These authors have contributed equally to this work 
Any correspondence should be sent to Jean-François Guégan (jean-francois.guegan@inrae.fr) and Benoît de Thoisy (bdethoisy@pasteur-cayenne.fr)

Authors' contribution: BdT and J-FG equally contributed to the writing, they conceptualized this synthesis paper and wrote its first version. $O D, B R, J-F G, B d T, L E, L M, P Q$ wrote the first version of sections $1,2,3,4,5,6$, and 7, respectively. AL, DR, FB, STi, BdT contributed to the writing of section 1; $E R, A F, S G, B d T$, J-FG section 2; CF, BdT, PC and MN section 3; JM, AK, AC, BR, SG, STa, J-FG section 4; BdT, SB, GP, MG, PT, MD, PLT, RS section 5; LM, SP, YE, EH, ID section 6; LC, MD, CF section 7. All authors contributed to the final version of the manuscript and approved the final manuscript.

\section{Abstract}

French Guiana is a European ultraperipheric region located on the northern Atlantic coast of South America. It constitutes an important forested region for biological conservation in the Neotropics. Although very sparsely populated, with its inhabitants mainly concentrated on the Atlantic coastal strip and along the two main rivers, it is marked by the presence and development of old and new epidemic disease outbreaks, both research and health priorities. In this review paper, we synthetize 15 years of multidisciplinary and integrative research at the interface between wildlife, ecosystem modification, human activities and sociodemographic development, and human health. This study reveals a complex epidemiological landscape marked by important transitional changes, facilitated by increased interconnections between wildlife, land-use change and human occupation and activity, human and trade transportation, demography with substantial immigration, and identified vector and parasite pharmacological resistance. Among other French Guianese characteristics, we demonstrate herein the existence of more complex multi-host disease life cycles than previously described for several disease systems in Central and South America, which clearly indicates that today the greater promiscuity between wildlife and humans due to demographic and economic pressures may offer novel settings for microbes and their hosts to circulate and spread. French Guiana is a microcosm that crystallizes all the current global environmental, demographic and socioeconomic change conditions, which may favor the development of ancient and future infectious diseases.

\section{Key-words}

French Guiana, global change, anthropogenic pressures, emerging and reemerging infectious diseases, epidemiologic transition. 


\section{Introduction}

French Guiana is a European ultraperipheric region located on the northern Atlantic coast of South America. It borders Brazil to the east and south, and Suriname to the west, and forms with Suriname and Guyana the "Guianas", belonging to the Guiana Shield landmass. On the Western part of the Guiana shield, French Guiana is the largest outermost European Union region, with a surface area of $83,534 \mathrm{~km}^{2}$, a population of 290,691 inhabitants and a very low population density of 3.5 people per $\mathrm{km}^{2}$, according to the 2020 census. Located between $3^{\circ}$ and $6^{\circ}$ latitude north $/ 51^{\circ}$ and $55^{\circ}$ longitude west, under an equatorial climate, rainfall interannual fluctuations are partly associated with the EI Niño global atmospheric circulation phenomenon. During El Niño periods, it is expected that the climate becomes hotter and drier, whereas during La Niña periods, the climate becomes cooler and wetter. El Niño-Southern Oscillation (ENSO) is the best-known example of quasi-periodic natural climate variability on the inter-annual time scale, and El Niño events occur at intervals of 2-7 years in South America (Bovolo et al., 2012).

The coastal area is narrow, at the transition between the northern boundary of the Precambrian Guiana shield and the recent Pleistocene-Holocene alluvial plain (Prost and Lointier, 1987), and is covered with mangroves, swamps and savannahs, and marsh and transition forests. Most of the remaining territory is occupied by upland moist forests (Guitet et al., 2016), which remain largely pristine and inaccessible compared to other Amazonian countries (Hansen et al., 2013). The Guianas region is characterized by high levels of species richness and endemism, and it is a high priority for the conservation of Amazonian biodiversity (Lopez-Osorio et al., 2010). The majority of people live on this $\sim 50-k m$-wide strip, which concentrates the main villages and cities as well as the country's economic activities; most of the remaining population lives along the two main rivers, the Maroni at the Surinamese border and the Oyapock at the Brazilian border, for a total surface of urbanized areas of $1,300-1,400$ ha (i.e. less than $0.02 \%$ of the territory) (AUDEG, 2019).

Occupation and conquests are a constant component of the history of French Guiana. The colonization by the former Amerindian groups started in the late third century. The first French occupations occurred at the beginning of the seventeenth century. The late 1970s and early 1980s were marked by displacement of Hmong refugees from Laos while the late 1980s saw a massive arrival of Surinamese refugees related to the Surinamese Civil War. French Guiana is fascinating in the contrasts characterizing this land of human migration, currently undergoing substantial population flows, although in recent years the migratory balance is almost nil. It is still facing significant problems of ille- 
gal immigration, lack of infrastructures, high living costs, and common social and economic unrest. Populations living 50\% below the national poverty level (Aiudoux et al., 2020), among which $35-50 \%$ are undocumented (Cambrézy, 2015), can coexist in close proximity to modern technology and infrastructures (e.g. the European Ariane 5 and Vega and Russian Soyouz joint launching rocket areas).

French Guiana's current population's largest ethnic group ( 50\%) comprises mixed descendants of African slaves and people of European ancestry, called "Creoles". Those born in Metropolitan France make up $9-10 \%$ of the population; $3-4 \%$ come from the French Caribbean territories (Guadeloupe, Martinique) and the Lesser West Indies (St Lucia, Dominica). Finally, $>30 \%$ come from several foreign countries, primarily Suriname, Brazil, Haiti, and Guyana. Chinese (3-4\% of the total population) make up the main Asian community followed by people from Laos (1-2\%) and East Indians, Vietnamese and Lebanese. In the interior territories, the main groups are the Maroons (Saramaka, Paramaka, Djuka, Aluku), descendants of runaway African slaves (7-8\%), and the Amerindians (3-4\%), who comprise the native peoples of French Guiana, distributed into six ethnic groups (Wayãpi, Wayana, Teko, Kali'na, Palikur, Arawak-Lokono). Although the population is small, population growth was +3.95\% between 1999 and 2006 (Cambrézy, 2015), and +2.6\% during the 2010s, a rate in the "top30" of the world in 2019 (World Bank, 2020). This demographic dynamism is mostly due to the very high birth rate - the highest in Latin America with Guatemala - with substantial migration fluxes of natives from Haiti, Brazil, and Suriname in search of better living prospects. This recent demographic evolution is both an opportunity and a challenge for French Guiana. The territory also has the highest gross domestic product per capita in South America, which largely explains its attractive potential on the continent.

The human growth impact on natural habitats and wildlife is increasing. Fire regimes, agricultural practices, invasive species, and infrastructure development threaten savannah habitats (Stier et al., 2020) and have resulted in $7 \%$ habitat loss during the last two decades. Logging, illegal gold mining and human encroachments, smallholder agriculture, and settlements are the main threats to forest habitats and biodiversity (de Thoisy et al., 2010), and forest loss during the last two decades is roughly estimated at 72,000 ha, i.e., $1 \%$ of the total forest cover. However, in addition to deforestation and habitat loss, the spatial extent of other threats on wildlife (e.g., harvest, habitat fragmentation, pollution) indicates that areas ensuring long-term maintenance of vertebrate populations decreased from $86 \%$ to $82 \%$ during the same period (de Thoisy et al., 2010), resulting in conservation concerns for some species (IUCN France et al., 2017). Although forestry is an important component of regional development, deforestation rates are likely to increase in the future with significant impacts on the local economy as well as habitat and biodiversity loss. Through higher exposure of human communi- 
ties (e.g., deforestation for agricultural development, traditional ways of life such as hunting and nonligneous product gathering and leisure, e.g., tourism, forest trips), all these activities should impact health conditions.

From a public health point of view, French Guiana is characterized by a mix of tropical parasitic and infectious diseases, e.g., Chagas disease, leishmaniasis, hantavirus disease, Q fever, Buruli ulcer, leprosy, Amazonian toxoplasmosis, malaria, which overlap with more widespread infectious diseases, e.g., dengue, HIV/AIDS, tuberculosis, Zika, chikungunya, and a social and economic context that favors the development of chronic diseases, e.g., alcoholism, poor dietary habits, and drug addiction. It is also characterized by the implementation of several control programs and health care measures that, as a corollary of positive impacts on individual and collective health, may exert a high selective pressure favoring the emergence of resistance against commonly used drugs and insecticides.

This pocket land-square region is thus a microcosm that concentrates all the environmental, ecological, anthropological, and socioeconomic conditions and their dynamics, a mix of the current continent-wide conditions. It is a cocktail of a society on the move and where important dynamics come together to facilitate the development of old or new emerging infections. Today, three important health problems are present separately or in synergy, facilitating the development of infections ( $\mathrm{Na}$ cher, 2020): (i) health infrastructures and work forces that are not sufficient or adapted to meet current needs, (ii) the fact that migrations and a cross-border pendulum or seasonal mobility may also contribute to introducing and dispersing new infections into the Guiana Shield region and beyond, and (iii) the economic and social conditions of these new arrivals, many of whom live in poverty and insalubrity comparable to what prevails in the poorest regions of Central and South America.

We propose a synthesis of the most recent research advances on zoonotic and vector-borne (ZVB) parasitic and infectious diseases in French Guiana. Most significantly, several national research programs have been set up to study the relationships between French Guiana's ecosystem dynamics, biodiversity, and human health in a rapidly changing societal and economic environment. These programs started in the early 2000s, but in 2010 very substantial support from the French government allocated funds to better understand the biodiversity-disease relationships through a Laboratory of Excellence award called "Center for the Study of Amazonian Biodiversity" (CEBA), using a One Health and Ecohealth perspective (Guégan et al., 2020), thus developing integrative and transversal approaches on several selected disease systems facing significant regional and global change. To address such complex, multiscalar and multidisciplinary issues, we developed a pathogeography approach (Murray et al., 2018) inherited from ecology and using the BAM (Biotic, Abiotic, Movement) 
framework as proposed by Sobéron \& Peterson (2005) to identify conditions suitable for disease maintenance and dispersal. Contrasting with general geographical trends observed for contagious diseases and their spatial distribution (Guégan et al., 2020), anthropic pressures on the environment and biodiversity can play significant roles on ZVB pathogens at local geographic scales and thus modify the complex balances between hosts, vectors, and disease agents (Kilpatrick et al., 2017). The aim of this integrative and multidisciplinary research activity in French Guiana was to investigate the relative importance of the three BAM compartments using several ZVB disease models.

Here, we will present the most significant research advances produced over the last two decades, structured in seven parts. Once having presented (1) the latest analytical tools, based on high-output molecular and serological methods to characterize ZVB disease agents, their hosts and vectors, and (2) new statistical and mathematical tools and analysis that have been developed to understand disease spread, we will explore the dynamics of several ZVB systems, using the BAM framework. Then we will discuss (3) climate variability and changes posing a major threat in French Guiana and how these new environmental conditions may impact disease systems (4) at the local scale with habitat changes that disrupt host and vector species communities, ecological networks, and natural cycles of pathogens, as explored with several iconic illustrations. After explaining abiotic and biotic factors, we will present societal factors: (5) traditional (e.g., hunting, agriculture) and extractive activities (e.g., gold mining) and human settlements at forest edges, (6) misused drugs and uncontrolled delivery inducing resistance, and (7) international migration and global trade, all of which are at-risk behaviors and practices that can be seen as proxy movement components within the BAM framework.

To conclude, research recommendations and actions will be proposed to better understand ZVB disease systems in new ecological-human settings altered by regional and global change, to make it possible to better control them and avoid new epidemic outbreaks.

\section{New tools for exploration of pathogen distribution and occurrence}

Detection of known pathogens is increasingly based on highly specific molecular diagnostic assays, often a gold standard for pathogen identification in clinical samples. However, these methods are not designed to detect pathogens differing from known species: they fail to detect nontargeted pathogens and this limitation makes diagnosis of novel, or emerging, pathogens difficult. Since wild fauna's microbial diversity in French Guiana is largely unexplored, one can assume that the diversity 
of noninventoried ZVB pathogens may be considerable. Recent surveys of microbial diversity are continually uncovering new pathogens that are related to previously recognized species, substantially expanding the tree of major pathogen lineages. Several novel pathogen identification and disease diagnostic tools are now widely used, including massive sequencing of full or partial DNA/RNA contents (e.g., virome, bacteriome) and a high-throughput serological approach.

Amazonia encompasses one of the greatest diversities of putative vertebrate reservoir species that can be correlated with high diversity of potential ZVB pathogens (Bergner et al., 2020; Han et al., 2016). One major realization of just how diverse and unexplored pathogens are comes from microbial DNA/RNA barcoding studies. For instance, early metabarcoding approaches have shown that the Cayenne tick Amblyomma cajennense harbors complex bacterial communities (Binetruy et al., 2019). While most bacterial diversity is living on tick cuticle, the internal organs of the Cayenne tick commonly harbor intracellular bacteria, including a member of the Rickettsia genus that is closely related to the etiological agent of epidemic typhus, R. prowazekii (Binetruy et al., 2019, 2020a). While the pathogenicity of Rickettsia of the Cayenne tick is currently unknown, this species commonly feeds on diverse vertebrate species and may serve as an ecological bridge for a zoonotic transmission from wildlife to humans and domestic animals. A further examination of bacterial diversity in 22 tick species in French Guiana demonstrated that at least 19 Rickettsia genotypes are circulating and that none were $100 \%$ identical to already known Rickettsia species or strains, including those detected early in Brazil (Binetruy et al., 2020a). While some ticks hosting these Rickettsia genotypes are among the most common species that bite humans in French Guiana, their potential pathogenicity still remains to be investigated.

Bacterial metabarcoding investigations on ticks in French Guiana also reported widespread novel pathogens of other bacterial genera, such as Candidatus Borrelia mahuryensis, which is closely related to the Lyme disease agent, B. burgdorferi (Binetruy et al., 2020b), although so far there are no Lyme disease cases in French Guiana. This new Borrelia species is common in the Cayenne area and was found in several tick species that feed on a broad variety of mammal and bird species, including migratory birds moving to North America. While Borrelia bacteria are tick-borne zoonotic agents causing Lyme disease (LD) and relapsing fevers (RF), whole genome sequencing indicates that Cand. Borrelia mahuryensis is divergent from the LD and RF Borrelia species: it is an intermediate taxon harboring a unique mixture of LD- and RF-specific genes, indicating that it may impact a wide host spectrum of American mammals and even humans (Binetruy et al., 2020b). Metabarcoding approaches also showed that ticks do not only carry pathogens: a diverse group of commensal and symbiotic microorganisms is also present (Binetruy et al., 2020c). These nonpathogenic microbes are 
even numerically more abundant in these vectors than pathogens. However, unlike pathogens, their biology and their effect on ticks remain largely unexplored and are often neglected (Bonnet et al., 2017; Gottlieb and Duron, 2020).

Amazonia is one of the least studied regions in terms of viral diversity. Studies have been conducted on bats but only emphasizing their putative reservoir role (Bergner et al., 2020; Bollati et al., 2020; Salmier et al., 2017). In French Guiana, a first virome analysis was done on feces and saliva samples of two bat species, the common vampire Desmodus rotundus and the insectivorous Molossus molossus. Fifty-one viral families were identified among which 14 are known to infect mammals. However, no virus known to be pathogenic in humans was identified in this study. A high proportion of plantand insect-related viral families was detected in $M$. molossus and a high proportion of vertebraterelated viral families in $D$. rotundus, highlighting the influence of diet in shaping bat viral diversity. Phylogenetic analysis on several viruses known to infect vertebrates (Nairoviridae, Circoviridae, Retroviridae, Herpesviridae, Papillomaviridae) support the idea of the importance of diet, together with host phylogenetic closeness, in shaping viral diversity (Salmier et al., 2017). A similar approach was carried out on kidney, spleen, and sera samples of seven rodent species from different habitats with different levels of disturbance (Tirera et al., in prep). Forty-one viral families were identified and 12 were known to strictly infect vertebrates. The different viral families, whether they originate from bacteria, invertebrates, plants, or vertebrates, were not evenly distributed within the different species and habitats. These differences in viral families' distribution could be explained by the ecology of the viruses themselves (i.e., ability to infect host cells and to persist and replicate) and by the ecology and behavior of their rodent hosts in some specific habitats, such as increased contacts with vectors and direct infection by arthropod-borne viruses or modified diet in disturbed environments. Viral diversity indexes and the relative dominance of viral species are also explained by the level of environmental disturbance and the habitat types, with the highest diversity index encountered in pristine forest habitats compared to disturbed ones.

In French Guiana, as in other South American regions, human populations are exposed to numerous infectious diseases. These can be endemoepidemic such as malaria, dengue, and other arboviruses (Mayaro, Tonate, and yellow fever), or emerging viruses such as the recent introduction of chikungunya, Zika, Oropouche, and SARS-CoV-2 causing COVID-19. These infectious diseases are almost always translated by fever, a symptom that dominates the clinical picture. Nevertheless, a nonnegligible proportion (40\%) of febrile states remain unexplained despite testing specific human pathogens using qRT-PCR or serology targeting viruses known to circulate in the Guianas region. The use 
of next-generation sequencing (NGS) in clinical samples with fever of unknown origin may allow the identification of untested viruses and possibly novel emerging infectious agents.

A metagenomic study is currently being conducted on plasma from patients in the French Army and their families based in French Guiana, showing symptoms of viral infections of unknown origin. The first results obtained on 19 sera identified Adenoviridae, Anelloviridae, Herpesviridae, and Parvoviridae (Lavergne and Rousset, unpublished data) that were previously detected in other virome studies in South America (Fahsbender et al., 2020; Phan et al., 2017; Yozwiak et al., 2012). This type of metagenomic analysis will improve our knowledge on viral, bacterial, and fungal agents circulating in this region and will result in improved diagnostic capabilities for the population.

Large-scale serological surveys on human populations may help identify viral circulation. Indeed, serological investigations provide baseline data on the distribution of immunity within a population, allowing deciphering history of past events and assessing the potential for future epidemic spread. Over the last few decades, French Guiana has experienced a succession of arboviral epidemics such as dengue (DENV) outbreaks, and more recently chikungunya (CHIKV), Zika (ZIKV), and Oropouche (OROV) viral emergence combined with endemic circulation of Mayaro (MAYV), Tonate (TONV), and yellow fever (YFV) viruses. The circulation of viruses belonging to the same genus such as Alphavirus with CHIKV, MAYV, and TONV or Flaviruses with DENV, ZIKV, and YFV in the same geographic area challenges both serological diagnostics and epidemiological surveillance, given that antibodies against antigenically related viruses can cross-react, given potentially false-positive results.

A serological survey combining classical and high-throughput serological approaches was performed to determine the level of circulation of arboviruses in French Guiana of MAYV, CHIKV, and ZIKV (Flamand et al., 2019; Hozé et al., 2020). These epidemiological studies, conducted on nearly 2,700 sera collected from individuals from all age groups in French Guiana, used in first intention an inhouse microsphere-based multiplex immunoassay (MIA). This system (Multiple Analyte Profiling technology (xMAP; Luminex Corp., Austin, TX, USA) allows simultaneous detection of several dozen analytes in a single well, making it possible to limit the quantity of samples required. Sub-panels of sera were further evaluated through microneutralization tests against viruses of interest in order to minimize false-positive results related to cross-reactions. Analysis of serological data obtained for potentially cross-reacting viruses coupled with modeling data on the age and location of participants made it possible to reconstruct the history of virus circulation and to assess the extent of crossreactivity. Identification of areas of wide circulation such as remote forested areas for MAYV can help 
public health authorities improve the performance of the surveillance system and better interpret surveillance data for future outbreaks (Hozé et al., 2020).

\section{Modeling infectious diseases in French Guiana: spatial and temporal pre- dictions of zoonotic and vector-borne diseases, and risk assessment}

A central issue in disease ecology is to understand the effects of the environmental spatial structure on host-parasite encounter rates and disease spread (White et al., 2018). The spatial distribution of the different habitats and the level of disease transmission risk are indeed essential determinants to be accounted for when modeling the spread of vectors and/or parasites (Karl et al., 2014). To this extent, graph theory or multiscale spatial pattern identification in vector distribution coupled with the factorial analysis of a hierarchically structured set of variables are ideal frameworks to account for "true" heterogeneities inferred from spatial analyses based on remote sensing and field studies, as exemplified on Chagas disease vectors in Bahia, Brazil (Roux et al., 2011). Typically, in the graph theory approach, geolocalized dwellings can be associated with nodes linked by edges defined with respect to vector or host dispersal capacities. Applying techniques originating in statistical physics for simplifying space, such as mean field approximations or cluster variation methods (Goldenfeld et al., 1999), allows predicting the global dynamics of the disease agent with respect to the spatial structures of the environment and heterogeneity in risk factors. This approach carries a strong potential to better understand and control endemic transmission of vector-borne parasites that typically afflict forest and rural populations of French Guiana and arboviral epidemics repeatedly spreading along the Atlantic coastal strip.

The transmission networks of ZVB parasites in French Guiana typically involve highly diverse host and vector communities (Chavy et al., 2019a; Peneau et al., 2016). How such biodiversity and its potential changes can affect parasite transmission is a central topic in today's disease ecology (Johnson et al., 2015). A delicate quantitative balance arises when noncompetent host species are added to the community as they can both increase vector abundance and dilute the spread of parasite by being refractory to infection (Randolph and Dobson, 2013). Integrative field and molecular studies have recently shown that more diverse host communities enriched in noncompetent species are associated with lower prevalence of Leishmania and Trypanosoma (see section 4 for further explanation). Graph theory could help decipher such antagonistic patterns because it already provides a highly flexible way of representing networks of ecological interactions shaping species communities and 
metacommunities (Ushio et al., 2018). This would also establish a link between space-time modeling in epidemiology and metacommunity models coming from ecology and population genetics, a promising line of research that remains to be explored in French Guiana.

The spatial distribution of the transmission risk of infectious diseases results from various spatialized processes, such as ecological processes determining the distribution of vectors and reservoirs, the mobility and sociospatial patterns of human populations, as well as supply and access to care inequalities. Some key elements of these processes are directly or indirectly observable by satellite remote sensing. Indeed, remote sensing offers, through a wide variety of sensors, the possibility of observing the Earth's surface and atmosphere in an almost continuous and complete way, with various and increasingly fine spatial, temporal, and spectral resolutions (see section 3 ). In particular, it makes it possible to characterize land cover and use, meteorological conditions, intensity, and type of human occupation, all elements involved in the functioning of eco-epidemiological systems (Dietrich et al., 2018; Parselia et al., 2019). In French Guiana, integration of satellite remote sensing data into the study of infectious diseases, particularly ZBD diseases, began in the early 2000s and has been particularly active.

The satellite data used were mainly SPOT-5 optical images (10-m spatial resolution) (Girod et al., 2011; Stefani et al., 2011) and more recently combinations of optical and radar images provided by the SPOT-5, Pleiades, ALOS/PALSAR, and Sentinel satellites (Li et al., 2016; Catry et al., 2018; Ballère et al., 2021). These images have been used to map land cover and land use (LCLU), all involving human intervention at some point in the classification process, particularly due to the significant cloudiness in the region limiting the applicability of fully automatic methods. In addition to these LCLU maps, several already available remote sensing-derived products were used: a digital elevation model and geomorphological landscapes from the Shuttle Radar Topography Mission (SRTM) (Guitet et al., 2013); land use from the VEGETATION sensor onboard the SPOT-4 satellite (1-km spatial resolution) (Gond et al., 2011); and the human footprint (de Thoisy et al., 2010).

As examples, landscape characterization has made it possible to objectively design the sampling for the capture of Anopheles, with the aim of inventorying species (Roux et al., 2013). The relationship between landscape characteristics and entomological data has led to confirmation of the significant link between landscape characteristics and the relative presence and density of the different Anopheles species (Roux et al., 2013); mapping the habitat quality and the presence probability of malaria vectors - in particular An. darlingi, the main malaria vector in the region - throughout French Guiana (Moua et al., 2017) and in the Cayenne area (Adde et al., 2016b), respectively; and dynamic 
mapping of anopheline density, considering meteorological time series from in situ observations (Adde et al., 2016c). The question of exposure risk was addressed through the construction of a spatialized index related to the landscape component of the exposure risk of human populations to mosquitoes (Li et al., 2016). Finally, the value of directly linking remotely sensed data with disease incidence has been demonstrated at a very local level, by studying a cohort of children under 7 years of age and making assumptions about suspected transmission sites (Stefani et al., 2011).

While the spatial and temporal distribution of prevalent infectious diseases can easily be studied from routine surveillance data collected by monitoring systems (see section 3), for low-prevalence diseases, more difficult to survey, it may sometimes be necessary to combine age-stratified serological surveys and mathematical modeling approaches. Although the detection of pathogen-specific antibodies cannot identify the date of infection for seropositive individuals, it is possible to implement specific methods to reconstruct the history of circulation. Serocatalytic models are perfectly adapted to this reconstruction, which is useful for determining annual variations in the force of infection (Hens et al., 2010) and studying the impact of spatiotemporal determinants of transmission on the evolution of this force of infection. This kind of approach, already used to reconstruct the transmission of chikungunya in the Philippines (Salje et al., 2016) and Chagas disease in Colombia (Cucunubá et al., 2017) has recently allowed, based on a blood bank resulting from a large arboviral seroprevalence study in French Guiana, frequent spillovers for MAYV by supporting the scenario of a sylvatic transmission cycle (Hozé et al., 2020).

Last, methods derived from ecological modeling have been used to explore the drivers of the dynamics of complex infectious diseases, with uncovered knowledge of the extent of vector and reservoir diversity and competence. Ecological Niche Modeling (ENM), based on an adequate set of BAM explicative variables of the distribution of cases, may have potential for highly confident predictive values of at-risk areas. These models also evidence that, although ZVB disease distribution is at a coarse scale mainly explained by climatic drivers, biotic variables and interactions between the wild components of the cycle and the human cycle affect the occurrence to a much lesser extent. Availability of real-time spatial information on these drivers may make it possible to propose epidemiological risk maps (Chavy et al., 2019a; de Thoisy et al., 2020).

\section{Short- and medium-term climate patterns drive disease dynamics in French Guiana}


Climatic conditions constrain the geographic and seasonal distributions of many infectious diseases, and weather affects the timing and intensity of disease outbreaks (Wu et al., 2016). Some specific pathogens are carried by vectors or require intermediate hosts to complete their lifecycle, and relevant climatic and weather conditions are necessary for the survival, reproduction, geographic distribution, and transmission of ZVB diseases (Murray et al., 2018). Whereas some studies have found that long-term climate warming tends to favor the geographic expansion of several infectious diseases, others have shown no relation or even an opposite trend (see Franklinos et al., 2019 for a recent review).

Four important infectious diseases causing human morbidity and mortality in French Guiana have been analyzed separately in order to investigate the temporal correlations between the number of disease cases and ENSO: three vector-borne diseases (malaria caused by $P$. falciparum and/or $P$. vivax, cutaneous leishmaniasis, and dengue fever) and a water-borne infection (Buruli ulcer due to an environmentally persistent Mycobacterium). All these studies were observational, retrospective, ecological, and most were collected from a multi-source surveillance system coordinated by the Regional Public Health Agency and based on confirmed cases diagnosed at Cayenne General Hospital: most of the situations illustrated in this paper stem from this surveillance system. These studies used ARIMA time series or more sophisticated mathematical models for this purpose. All disease systems showed consistent temporal correlations of El Niño oscillations with disease cases, thus highlighting French Guiana as one of the best-studied regions in the world for the impact of ENSO on distinct human infections.

Even if there is evidence that ENSO is associated with increased risk of malaria in South American countries (Bouma and Dye, 1997; Bouma et al., 1994, 1997; Gagnon et al., 2002; Poveda et al., 2001), Hanf and colleagues' work was the first to really highlight an effect of the El Niño phenomenon on malaria epidemics in French Guiana. As measured by the Southern Oscillation Index (SOI), P. falciparum cases were negatively associated with SOI, with a time lag of 3 months from 1996 to 2009, but ENSO was a very poor predictor of malaria case numbers, explaining only $4 \%$ of the variation in disease incidence. This suggests that a large part in malaria cases was best explained by nonclimatic causes but essential human activities (Hanf et al., 2011).

The impact of interannual climatic variability associated with ENSO on visceral leishmaniasis has been analyzed in Brazil (Franke et al., 2002). Other studies have demonstrated that vector densities and several environmental variables (Feliciangeli and Rabinovich, 1998; Rabinovich and Feliciangeli, 2004; 
Salomon et al., 2004) were correlated with the number of cases of leishmaniasis in Venezuela and Argentina. In Columbia, Cardenas and colleagues (2006) showed that during El Niño episodes leishmaniasis increased, whereas during La Niña periods it decreased. Concerning French Guiana, Roger et al. (2013) used both the Multivariate EI Niño/Southern Oscillation Index (MEI) and the SOI between January 1993 and December 2010 to evaluate the influence of ENSO on the number of cutaneous leishmaniasis case. They showed that infections were positively associated with temperature and MEI (i.e., positive MEI is correlated with El Niño episodes) with time lags of 8 and 4 months, respectively. In contrast, disease cases were negatively correlated with rainfall, with a 2-month lag and with the number of days with rainfall $>500 \mathrm{~mm}$, with lags of 4 and 7 months. Also, the strongest correlations were observed in March for rainfall and in November for MEl. These authors conclude that the introduction of climatic variables into their model improved the multivariate model precision by only $12 \%$.

Dengue ecology is one of the best-studied vector-borne disease systems in the world, and its viral transmission is influenced by a complex interplay of both intrinsic (e.g., human and vector demographics, virus properties) and extrinsic (e.g., environmental, meteorological) factors (Flamand et al., 2014). Interactions between climate and dengue fever epidemics have been studied worldwide (e.g., Banu et al., 2011; Campbell et al., 2015; Cazelles et al., 2005; Descloux et al., 2012; Gharbi et al., 2011; Hales et al., 1996; Johansson et al., 2009). Overall, all these studies confirmed that the effects of climatic parameters on dengue incidence depend largely on local contexts and epidemiological patterns. Several studies have suggested that El Niño events play a role in dengue fever epidemics on the South American continent (Ferreira, 2014), and concerning French Guiana a synchronous positive association between the occurrence of El Niño events, warmer temperatures, less abundant rainfall, and dengue outbreaks was identified (Gagnon et al., 2001). A more recent investigation demonstrated that climate has major effects on the occurrence of dengue epidemics in French Guiana: maximum temperature, minimum relative humidity, global brilliance, and cumulative rainfall were all identified as determinants of dengue outbreaks, with the strongest correlations observed between disease incidence and these meteorological events after a 4- to 6-week lag (Flamand et al., 2014). Using a 23-year time series of dengue cases, this study demonstrated that in French Guiana the Niño 3 area index showed the highest correspondence with dengue incidence, with a significant negative correlation observed between dengue cases and rainfall in October and November (Adde et al., 2016a). This model was able to predict $80 \%$ of dengue outbreaks along the studied period but failed in predicting only $15 \%$ of incidence in nonepidemic years. There is an association between dengue epidemic years and El Niño events in French Guiana, but it is impossible to accurately predict dengue fever incidence dynamics in the human population. 
Finally, Buruli ulcer is a skin disease prevalent in tropical regions caused by M. ulcerans, a bacillus that persists in aquatic environments such as river flood plains and swamps. When people are exposed to contaminated areas they may contract and develop skin ulcers. Deep ulcers can cause scarring of muscles and tendons, resulting in permanent disability. The mechanism by which $M$. ulcerans is transmitted from the aquatic environment to humans is not known; however, Garchitorena et al. (2015), estimating statistical models of the different potential transmission pathways of the bacillus to humans in Cameroon, central Africa, clearly demonstrated that environmental transmission best explains the temporal and spatial patterns of cases better than an accepted, but still controversial insect transmission. Statistical phase analysis for Buruli ulcer in French Guiana suggested a preceding relationship of rainfall change occurring before disease cases. Over the disease time series, a belowaverage sea surface temperature (SST) value (indicating a La Ninã episode) produces a higher than average level of Buruli ulcer cases after a time lag of approximately 18 months. Conversely, a peak in the SST value (indicating a El Niño episode) creates a decline in the 4-year oscillation of cases. Overall the results suggest that outbreaks of Buruli ulcer over a long period (at least 2 years) correspond with a decline in SST 17-18 months prior, while the opposite is also true: an increase in SST is associated with a below-average decrease in disease cases over the preceding 4 years. Based on Buruli ulcer cases for the 1969-2012 period, the longest time series known in the world for this disease, it was shown that complex interplays between stochastic SST and the influence of long-term rainfall in addition to seasonal drivers may drive Buruli ulcer disease patterns in this region (Morris et al., 2014a). Long periods of wet weather (as observed in many tropical regions) followed by a decrease in rainfall may increase the number of stagnant water bodies and swampland, flowing rivers may reduce into a series of isolated pools, which could favor the development of abiotic and biotic conditions promoting the development of the bacillus in the environment and/or contacts by susceptible and exposed people.

\section{Animal species communities and zoonotic and vector-borne diseases in French Guiana}

ZVB diseases are sensitive to habitat disturbance (Guégan et al., 2020). One key reason is the responses to environmental changes of animal species involved in the disease cycle. Modifications in the distribution of natural resources, simplification of ecological niches, and microclimatic variations could favor the expansion of more generalist host and vector species, and the reduction or disap- 
pearance of more specialized, less resilient ones. Most ZVB diseases rely on a restricted range of efficient reservoir and vector species, but many other species may act as hosts, especially in cases of ecosystem disequilibrium. The potential impacts of biodiversity alteration on zoonotic disease transmission were conceptualized with the "dilution effect hypothesis" (Schmidt and Ostfeld, 2001), which states that higher biodiversity should generally reduce infectious disease transmission through the presence of poorly competent hosts acting as epidemiological dead ends or slowing the disease agent cycle. This idea received much attention, but also triggered criticisms claiming that the biodiversity-disease relationship was idiosyncratic due to other mechanisms that could instead lead to amplification of disease transmission with increasing biodiversity (Randolph and Dobson, 2012; Wood et al., 2014).

In French Guiana, an extensive literature is available on the putative or confirmed roles of animal species as carriers of a large set of microbes, including bacteria (Christen et al., 2020; Davoust et al., 2014; Gay et al., 2014; Schaub et al., 2020), parasites (de Thoisy et al., 2003; Fandeur et al., 2000; Volney et al., 2002), and viruses (de Thoisy et al., 2009, 2014, 2016; Lavergne et al., 2015, 2016). An open list of infected species, from either molecular or serological evidence, is important to direct further research, but provides little information on the functional role of host or vector species and of species communities in the disease cycle and expected responses to habitat changes. Several major case studies nevertheless delved deeper into the role of wildlife in disease agent circulation and spread in this region.

Leishmaniases are a group of human diseases caused by parasites of the genus Leishmania (Trypanosomatidae) transmitted by hematophagous Phlebotominae sandflies. Leishmaniases are a significant burden in the Amazonian region, where several Leishmania species coexist with transmission cycles involving distinct sandfly vectors and wild mammalian reservoir hosts (Lainson and Shaw, 2010). These parasites have long been extensively studied in French Guiana, but the knowledge of leishmaniasis ecology in French Guiana has recently greatly improved with the use of new methodological and analytic methods (see section 1). Characterization of sandfly communities with metabarcoding (Kocher et al., 2017a), and detection and identification of Leishmania spp. (Kocher et al., 2017b) provided significant technical advances and original tools for the understanding of the disease cycle. Then it was shown that sandfly communities are under the influence of an ocean-inland gradient, with more coastal sites hosting widely distributed species, while at inland sites sandfly species show a more restricted distribution. Concerning only known Leishmania vector species in French Guiana (Ps. squamiventris maripaensis, Ps. ayrozai, Ny. umbratilis, Tr. ubiquitalis, Ps. panamensis, Vi. furcata, Bi. flaviscutellata) (Medkour et al., 2019a, 2019b; Rotureau, 2006) most vector species were predom- 
inantly found on the coast, with the exception of Vi. furcata and Ps. panamensis found farther inland. From a more ecological viewpoint, the abundance of the four vector species, Ps. squamiventris maripaensis, Ps. ayrozai, Ny. umbratilis and Th. ubiquitalis, is negatively correlated with the aboveground biomass, elevation, and the amplitude of periodic seasonality, in contrast to Ps. panamensis and Vi. furcata (Chavy et al., in prep). Second, blood meal analysis (Kocher et al., 2017c), revealed that sandflies can feed on a wide range of vertebrate host species, including some that are not known to act as Leishmania spp. reservoirs and may therefore contribute to diluting Leishmania transmission. Accordingly, the relative abundance of these "diluting" hosts in vertebrate communities correlated with lower parasite prevalence in sandflies. The relative abundance of these diluting host species also decreased in less diverse vertebrate communities, in which Leishmania reservoir hosts appeared dominant, in accordance with the dilution effect hypothesis. On the other hand, more diverse vertebrate communities were associated with higher sandfly densities. These antagonist "host dilution" and "vector densification" effects therefore seem to compensate each other locally, mediating the contrasting consequences of biodiversity changes on parasite prevalence and circulation.

The American trypanosomiasis, also known as Chagas disease, is a ZVB disease endemic in Latin America. The etiologic agent, Trypanosoma cruzi, can be transmitted by $>70$ species of generalist hematophagous triatomine bug species (Gourbière et al., 2010) that feed on $>170$ vertebrate host species with variable levels of susceptibility to T. cruzi (Browne et al., 2017). French Guiana, where Chagas disease prevalence can reach up to $7 \%$ in rural human communities (Aznar et al., 2004), is one of the 21 countries where transmission remains a significant public health concern (WHO, 2020). French Guiana constitutes a remarkable hot spot of vector diversity with 14 of the 27 known Amazonian triatomine species (Bérenger et al., 2009). The link between such diversity and the actual risk of transmission has been explored by integrating cross-sectional entomological and parasitological data into force-of-infection models (see Figure 1) (Peneau et al., 2016). While the overall abundance of triatomines did not vary across the main geomorphological landscapes, the species diversity of their assemblage significantly increased along a coastal-inland gradient, as similarly observed for sandfly communities (see above). The level of triatomine infection by $T$. cruzi also showed clear spatial heterogeneity, although the observed geographical trends turned out to be species-specific. Accounting for those concomitant entomological and parasitological trends in the modeling of landscape-specific forces of infection showed that the lowest risks of human infection were associated with triatomine communities of intermediate levels of species diversity (see Figure 1). The higher risks of infection found at lower and higher levels of bug diversity were readily explained by the high rates of infection of the key local species (i.e., Panstrongylus geniculatus) and by the increased contributions of two 
secondary vector species (i.e., Rhodnius pictipes and $P$. lignarus), respectively. An intriguing implication of this original pattern is that an increase in vector biodiversity could potentially dilute (at low diversity) or amplify (at high diversity) the transmission of $T$. cruzi. A formal integration of the above advances on the role of the triatomine community in French Guiana and of recent advances made in assessing T. cruzi dynamics in host communities (Gottdenker et al., 2012; Flores-Ferrer et al., 2019) is now critical to help meet the key challenge of controlling Chagas disease, which is transmitted by both highly diverse and mostly intrusive triatomine species. This reinforces the idea, already corroborated by the above study on leishmaniasis transmission, that a thorough assessment of the impact of biodiversity loss on ZVB disease transmission requires not only an understanding of the consequences of the alteration of host species diversity, but also of the concomitant changes in vector species assemblages (see Roche et al., 2013 for a comprehensive analysis).

Another illustration concerns rabies virus transmission by vampire bats in French Guiana. The importance of vampires in the maintenance and transmission of rabies in South America has been recently challenged, with mounting evidence of a role played by other species. Based on molecular and serological surveys on almost 1,500 bats from 30 species, RABV was molecularly detected in a common vampire and in a frugivorous bat in French Guiana. Species seroprevalence ranged from 0 to $20 \%$, and the risk of seropositivity was higher in bats with a hematophagous diet, living in monospecific colonies and in dense forests (de Thoisy et al., 2016). Together with those bioecological drivers, immunity gene characterization in several species suggested differential abilities to control viral infection (Sarkis et al., 2018). A longitudinal survey conducted in vampire colonies showed substantial temporal fluctuations in prevalence, with waves of seroconversions and waning immunity. These results suggest (i) frequent exposure of animals, (ii) the ability of the infected host to control and eliminate the virus, and (iii) more relaxed modes of exposure between bats than the commonly assumed infection via direct contact with saliva of infected animals (de Thoisy et al., 2016). RABV circulation is hypothesized to be principally maintained in the pristine forest habitats that may provide sufficient food resources to allow vampire bats, the main prevalent host species, to maintain and propagate RABV, at larger scales by vampire males and within bat colonies chiefly by females, as suggested by dispersal patterns (Huguin et al., 2018). On the forest edge and in disturbed areas, human activities may induce insidious effects such as defaunation. One of the ecological consequences is the disappearance of resources for secondary or tertiary consumers, and populations of vampires may then shift to alternative resources such as cattle, domestic animals, and humans. Therefore, intact forest allows both a dilution effect in highly rich bat communities and the maintenance of large bat-prey populations of medium-sized and large mammals, which should prevent their migration to anthropized areas (de Thoisy et al., 2016). 
A fourth example concerns Buruli ulcer (see also section 3). A nonlinear increase in the potential abundance of $M$. ulcerans has been observed under the anthropogenic stresses of land-use change and deforestation in French Guiana, making this study one of the most comprehensive but still rare demonstrations of the role of habitat alteration on the emergence of new infections (Morris et al., 2016a). This increase in pathogen abundance locally due to deforestation has been attributed to a concomitant rise of preferred hosts represented by predominantly low-trophic-level aquatic organisms that concentrate the bacillus (Morris et al., 2016b). The freshwater food-web collapse driven by land-use change in the different aquatic sites leads to a decline in the bacillus local trophic niche width, resulting in the decrease or disappearance of predators in the local sites directly impacted by deforestation. Since the natural process of predation, which reduces prey species and infected hosts, is no longer effective, it leads to an increase in the pathogen load in these man-made disturbed ecosystems. Here deforestation appears to be more important for this emerging infection to appear than the development of agriculture, i.e., slash-and-burn culture in the region, probably due to various threshold effects that may occur in animal and microbial species communities during land-use transformation.

\section{Extractive activities, edge effects: at-risks situations}

Most of the French Guiana population (85-90\%) lives in a $\sim 1,000-\mathrm{km}^{2}$ coastal strip and along the Maroni River, in human-modified areas (artificial, agricultural, and disturbed areas). Outside these areas, people live in small widely spread settlements close to forest edges, often with a traditional way of life and/or with extractive activities implying frequent contacts with forest ecosystems. These activities are diverse, varying in how widespread and intense they are, and include mining, fishing, hunting and gathering, slash-and-burn agriculture, logging, and tourism (de Thoisy et al., 2010); they have not only significant impacts on biodiversity but may also be risk factors. In more open habitats, such as savannah and flooded coastal forest, and in highly degraded habitats of the littoral and riverine areas, agriculture, deforestation, and legal and illegal settings also expose people to ZVB disease threats.

Gold mining is the main threat to natural habitats (Dezécache et al., 2017) and likely the most at-risk activity. Goldminers' strenuous working and living conditions lead to poor health caused by infectious and noninfectious diseases (Douine et al., 2017). Malaria outbreaks are common in remote 
villages and gold mining camps, where very local favorable conditions allow the initiation of malaria transmission among miners coming from Brazil, military personnel present on site attempting to reduce this burden of illegal activities, and even remote villages near these activities (Berger et al., 2012). Since 2008, French Armed Forces have been involved in military operations to control and reduce illegal gold mining activities in forested areas particularly exposed to malaria. In 2008-2014, a total of 1070 malaria cases were reported among the French Armed Forces: all of them occurred during or after a mission in illegal gold mining areas (Pommier de Santi et al., 2016a). Malaria among goldminers was hyperendemic in these areas, with more than $40 \%$ asymptomatic cases because there was no protection against mosquito bites and no access to diagnostic tests and antimalarial treatments (Pommier de Santi et al., 2016b). Anopheles darlingi is the main malaria vector in French Guiana (Vezenegho et al., 2016) and contributed to malaria transmission in illegal gold mining areas (Pommier de santi et al., 2016c), even during the day (Pommier de Santi et al., 2017). In these areas many other anopheline species are involved in malaria transmission such as An. marajoara (Pommier de Santi et al., 2016c), An. nuneztovari, and An. ininii (Pommier de Santi et al., 2016a), with very high infection rates (around 10\%). Wild monkeys surrounding forest camps have been suggested to be possible hosts and may maintain the parasite cycle at the edges of the camps and contribute to the local parasite pool, thus leading to transmission to humans (Fandeur et al., 2000; Volney et al., 2002).

Leishmaniasis was first described in French Guiana in 1943 (Floch, 1954). The annual incidence remained relatively stable, with an incidence of 15-20 new cases per 10,000 inhabitants between 1979 and 2006, and has recently declined to five to six cases (Simon et al., 2017). Cutaneous leishmaniasis was first described as a seasonal disease affecting humans penetrating the rainforest for professional (e.g., scientists, soldiers, foresters) or leisure activities (e.g., hunters, tourists) (Dedet et al., 1989), disturbing the sandfly vectors living in the forest canopy. The last few decades have shown an increase of human activities in the forest, especially with the gold rush (Hammond et al., 2007), and a significant change in at-risk populations. Gold mining activities foster the transmission of leishmaniasis from infected miners who may be infected by Brazilian Leishmania strains, thus allowing the circulation of parasitic strains across the border (Loiseau et al., 2019), underlining the need for transboundary strategies to minimize exposure for high-risk populations (Vasconcelos-dos-Santos et al., 2019).

The most illustrative human disease related to agriculture practices is the hantavirus pulmonary syndrome. In French Guiana, a new strain has been identified from human cases and two Sigmodontinae rodents, Oligoryzomys delicatus, and Zygodontomys brevicauda (Matheus et al., 2012). Although few cases have been reported, predominant exposure factors are related to cropping activities and slash- 
and-burn subsistence agriculture (Matheus et al., 2017). Mosaics of open vegetation types are indeed favorable habitats for these rodents. Small-scale ecological events and increased human pressure on these habitats may increase, both very locally and temporally, the likelihood of population expansion and virus spread (de Thoisy et al., 2014).

Leptospirosis is a bacterial zoonosis caused by Leptospira species, considered rare in French Guiana until recently, unlike other French territories in the French West Indies and Brazil (Le Turnier et al., 2018; Picardeau, 2013). The most common reservoir for Leptospira is Rattus norvegicus, but wildlife rodents and other small mammals likely play a role (Petrakovsky et al., 2014). The bacterium is found in most of the aquatic environments studied, in particular urban and periurban areas (Combe et al., 2019). Settlements with a high topological wetness index as well as proximity to agricultural activities and watercourses may be the main risk factors (Jagadesh et al., 2019). Gold mining was also identified as a frequent professional exposure (Turnier et al., 2018), since miners may also work in small tributaries and forest creeks, and black rats may be present in some forested areas in the vicinity of mining camps (Da Rosa et al., 2020). The year 2020 was accompanied by a peak in the occurrence of severe cases of leptospirosis in French Guiana, probably due to weather conditions causing more flooding than usual, but likely also because of a more systematic search for the disease by clinicians resulting from increasing awareness of this disease. Further studies are needed to identify its real incidence, to search for the animal reservoir, if any, and to identify probable local strains that have been ignored for the moment.

Wild meat consumption is a commonly accepted risk factor for parasitic infection (Gonzalez et al., 2020), but few cases are recorded in French Guiana. Wildlife hunting, handling (Kerr et al., 2015), use of wild animal parts for artifacts and traditional medicine (Cardona-Castro et al., 2009), and contact with armadillos has been suggested as a putative risk for Mycobacterium leprae transmission (Schaub et al., 2020). The main issue is likely the parasite Toxoplasma gondii (Carme et al., 2009). Molecular comparative approaches for Toxoplasma phylogenotyping highlight the particular highly diverse genetic structure of $T$. gondii in South/Central America, with the highest genetic diversity in the strains isolated from French Guiana and in the surrounding areas (Gala et al., 2019). An atypical French Guiana strain has been identified, responsible for a new disease in immunocompetent patients with frequent lung infection and potentially life-threatening pulmonary complications (Blaizot et al., 2020; Demar et al., 2007, 2008, 2012), which has a high virulence in mice models (Simon et al., 2019). The role of wildlife, with wild felids acting as reservoirs (Demar et al., 2008) and many vertebrate species as intermediate hosts (Mercier et al., 2011) has been demonstrated, highlighting insufficiently cooked wild meat consumption as a risk of parasitic transmission. Hybridization between Amazonian 
Toxoplasma strains hosted by edge-host species in forest ecotones and cosmopolitan strains hosted by domestic cats have also been described (Mercier et al., 2011) and may contribute to the spread of these pathogenic strains within riverine human communities.

Q fever, caused by the intracellular bacterium Coxiella burnetii, presents a very particular epidemiological profile in French Guiana (Eldin et al., 2017; Epelboin et al., 2016). Small domestic ruminants incriminated elsewhere are not involved in the epidemiological cycle in French Guiana, and the potential animal reservoir, still poorly understood, could be several wild species (Christen et al., 2020; Davoust et al., 2014; Pommier de Santi et al., 2016d). While the classically described risk factors for $Q$ fever are human contacts with domestic animals (e.g., by farmers, veterinarians, and slaughterhouse workers), in French Guiana those that have been identified were working in building construction or gardening and had wild animals in the vicinity (Christen et al., 2020), with men aged 30-60 years in the Cayenne area and people from metropolitan France being at greater risk (Epelboin et al., 2020). French Guiana also has the highest annual incidence rate in the world, with 30-40 cases per 100,000 inhabitants per year (Thill et al., 2019), and a more virulent and unique strain MST 17 leading to the most severe pulmonary impairment described worldwide. Paradoxically, this infection is very little described in the rest of South America, leaving the question of a French Guianese epidemiological specificity or a massive underdiagnosis on the rest of the continent unresolved (Epelboin et al., 2016).

These examples highlight that biodiversity-ecosystem relationships are also relevant at the genetic diversity level (Roger et al., 2012). At edges, hybridization and introgression between domestic and wild pathogen strains, host species richness, diversity of ecological niches in these ecological settings, may influence pathogen diversity (Mercier et al., 2011). The strain virulence of $C$. burnetii could result from selection pressure from the ecosystem with one dominant clone surviving and circulating among a few wild hosts. In contrast, the high diversity of $T$. gondii strains may be promoted by a wider host range, and optimizing colonization of edge microhabitats.

\section{Resistance in the Amazonian context: specific adaptive responses of para- sites and vectors under high selective pressure}

The Amazonian region has a number of vector-borne diseases that affect local populations. In the 1940s, a global campaign controlled yellow fever with vaccination and a DDT-based eradication cam- 
paign of Ae. aegypti (Epelboin et al., 2018). As a consequence of this campaign and systematic administration of amodiaquine in the 1960s, malaria was eliminated from the coastal area and pushed to the inland and riverine areas of French Guiana (Musset et al., 2014). In the 1950s, DDT-resistant Ae. aegypti recolonized the region and dengue fever became the major arboviral disease until 2013, when chikungunya followed by Zika viruses were introduced in the region. More recently, after these two large outbreaks, dengue has again dominated $(2019,2020)$ arbovirus-induced symptoms.

In the absence of vaccine, the first pillar for efficient malaria control is prompt diagnosis followed by effective treatment and eventually the interruption of vector-human contacts. On the other hand, in the absence of treatment and few available vaccines, vector control is the mainstay to control arboviruses. Therefore, for decades, parasites and vectors have been subjected to high selective pressure to control them, forcing public health authorities to adapt their tools and strategies over time. Historically, resistance emerges in endemic areas where malaria transmission is generally low. In fact, this low level of transmission leads to a low level of immunity in humans and higher frequency of symptomatic cases requiring antimalarial drug treatment. Sequentially, resistance to antimalarial drugs has been co-selected in Southeast Asia and Amazonia. While co-circulation of resistance and sensitive strains is generally observed in Asian and African settings, in French Guiana and more generally in the Guiana Shield, rapid fixation of the beneficial traits, i.e., resistance, is observed. This fixation precludes the re-expansion of the sensitive parasites, which no longer exist. As an illustration, chloroquine had been used in the world for decades against $P$. falciparum before the wide spread of resistance. This resistance has been linked in the genome to the pfcrt gene, which encodes the chloroquine resistant transporter. A ubiquitous K76T mutation has been observed worldwide. Depending on the resistance foci, compensatory mutations have been associated with K76T and generated pfcrt haplotypes specific for each endemic region (Ecker et al., 2012). In French Guiana, at the end of the 1990s, chloroquine was withdrawn and replaced with mefloquine because of observed resistance. At that time, the pfcrt K76T allele was fixed in the parasite population and associated with four other mutations. However, two decades later, despite the fixation of the pfcrt K76T allele, the prevalence of chloroquine resistance progressively dropped around $25 \%$. Using a genomewide association study with sensitive and resistant isolates, and genome editing, a new mutation in pfcrt encoding a C350R substitution has been identified (Pelleau et al., 2015). This mutation was associated with the restoration of $\mathrm{CQ}$ sensitivity. For the first time, a reversion process has been observed in Plasmodium spp. resistance to antimalarial drugs. The drivers of this strong selection process in this Amazonian context should be identified and studied. However, a number of factors could probably explain this particularity. One of them is the low complexity of infection observed among patients, which limits the recombination process during transmission to mosquitoes. Also, antimalar- 
ial drug usage is erratic in several settings on the Guiana Shield and mainly in the deep forest where people live far from health care services (Douine et al., 2018b). This erratic usage exposes parasites to several molecules and selection processes. While a mutation restores the sensitivity to chloroquine, it putatively confers resistance to another drug.

Similar to the parasite/antimalarial side, mosquito behavior and insecticide efficacy drive control strategies against the major vectors. An. darlingi tends to bite at night and is believed to rest indoors and breed in natural waters. Consequently, outside the inland forest, in high-risk areas, control is based on indoor residual spraying of insecticides and the distribution of impregnated bednets. Ae. aegypti is diurnal, lives in human environments, and breeds in human-made containers. Indoor and outdoor spatial spraying is performed during outbreaks and breeding site management is conducted throughout the year. After subsequent use of DDT and organophosphates, pyrethroids have become the mainstay against the two main vectors in French Guiana and at a larger scale. In addition, yearround pest control is implemented, and domestic insecticide aerosols are available with the same molecules. The massive pressure produced by the sole use of one type of insecticide is expected to select resistance phenotypes. However, vectors respond differently to insecticide pressure. An. darlingi has rarely developed resistance across its spatial distribution and is still mostly susceptible, except in Columbia where it harbors metabolic resistance to pyrethroid and organochlorate insecticide families (Fonseca-González et al., 2009; Orjuela et al., 2018, 2019). The constant renewal of susceptible genes from sylvatic populations is suspected to prevent resistance built-up (Epelboin et al., 2018). However, recently An. darlingi resistance to pyrethroid was reported for the first time in French Guiana, in St-Georges-de-l'Oyapock (Vezenegho et al., submitted). An. darlingi population genetic studies are currently evaluating the possibility of insecticide gene resistance spread throughout French Guiana. In contrast, Ae. aegypti populations exhibit a tremendously high level of resistance to deltamethrin (the only available and allowed drug against adult Ae. aegypti in France), which jeopardizes insecticide-based control. This high level is also observed in Oiapoque, a Brazilian border town with French Guiana, but not in Macapá, Amapá, 589 km away by road. The study of population genetics has shown a low gene flow among Ae. aegypti populations from the two countries, with the exception of the border towns of Oiapoque and St-Georges-de-l'Oyapock, suggesting local selection of resistance rather than migration (Salgueiro et al., 2019). This information is important to adapt vector control strategies in both countries. Today, the level of resistance in French Guiana is critical with the fixation of target-site mutations and co-occurrence with metabolic mechanisms (Dusfour et al., 2015; Guidez et al., 2020). Other paths are also being investigated to determine the implication of the microbiome in the detoxification of insecticides. The richness of Amazonian flora had also been explored to identify plant insecticides. Eight out of 85 plant species demonstrated larvicidal activities 
against resistant Ae. aegypti (Falkowski et al., 2020), notably the rainforest tree species Sextonia rubra (Lauraceae).

With the introduction of ZIKV, the possibility of viral emergence and eventually of other vectors has been raised (Epelboin et al., 2017). Some of these putative vectors live in the urban environment, bite at night but may be less anthropophilic and more exophilic than Ae. aegypti or An. darlingi, such as Culex quinquefasciatus. This particular Culicid species is known to adapt quickly to insecticide pressure (Guidez et al., 2020). A novel vector in the environment would deeply challenge the wellestablished vector control strategies as developed in French Guiana during the last few decades.

\section{Role of international travel, population movements, and immigration in the emergence and transmission of infectious diseases}

Climate change and ecosystem damage play definite roles in the risk of emerging epidemics but population movements, international transport, and trade globalization (the $\mathrm{M}$ component within the BAM concept) are also critical factors for the rapid spread of pathogens. At a global scale, they have brought individuals, vectors, food products, animals, and plants that are increasingly implicated in the spread of microorganisms across continents. While examples of rapid global expansion of microbial pathogens were once rare, greater human and capital movement has progressively broken down the barriers between species and ecosystems, increasing the incidence, geographic expansion, and host ranges of various emerging infectious diseases.

At a local level, population movements linked to migratory phenomena and the cross-border pendulum or seasonal mobility can also have an amplifying role for these emerging diseases, or at least make their control and elimination difficult (Saldanha et al., 2020; Wangdi et al., 2015). In French Guiana, migration, which has accelerated dramatically over the past three decades, is resulting in population movements on the borders of Suriname and Brazil. In addition to a very challenging economic situation ( $45 \%$ of the population lives below the poverty threshold, $20 \%$ do not have direct access to drinking water, the unemployment rate is over $22 \%$ ), this immigration is accompanied by strong growth in informal housing, which favors direct and indirect transmission of many infectious pathogens. 
Vector-borne infections are examples of pathogens that can be introduced into susceptible geographic areas by infected travelers where competent mosquitoes or arthropod vectors are present. In the last few decades, dengue fever, chikungunya, Zika, and yellow fever infections, which have expanded in distribution in risk areas, have illustrated various contributions to this dynamic process through the occurrence of epidemics in French Guiana (Epelboin et al., 2016). Another example is the maintenance or expansion of active malaria transmission linked to clandestine gold mining (see section 4) and cross-border movements (Mosnier et al., 2020).

Dengue fever is considered as the most important mosquito-borne viral disease affecting humans (Bhatt et al., 2013; Stanaway et al., 2016). Following its re-emergence in South America during the 1960s, the first dengue hemorrhagic fever cases were reported in French Guiana in 1992. The transmission then followed a seasonal pattern (see section 3) punctuated by epidemics linked to a cocirculation of several serotypes. Since the 1990s, epidemics occurred in French Guiana every 4-5 years, affecting nearly $10 \%$ of the population, mainly in costal urban areas (Santé publique France, 2020; Stanaway et al., 2016). The substantial public health burden related to these epidemics has led to the reinforcement of surveillance systems, making it possible to highlight that the re-emergence of a serotype in French Guiana originated from imported human cases from the French West Indies or neighboring countries (Suriname or Brazil). For example, since the last DENV-2 epidemic occurred in 2012-2013, the detection of biologically confirmed cases has gradually decreased to sporadic and then none after September 2016. In January 2019, two epidemiologically unrelated cases of dengue fever were detected, including one imported from the French West Indies. In late April, another case of DENV-2, imported from South America, was identified in Kourou; the epidemiological investigation conducted at that time identified a secondary case, the first indigenous case detected in the territory since 2016. A few weeks later, an epidemic broke out, probably after a case of DENV-1 imported from the French West Indies was detected in Cayenne. In the following months, several epidemic outbreaks related to these two serotypes occurred in the territory, with a total of over 1000 cases between January 2019 and April 2020, illustrating the spread of viral circulation (Santé publique France, 2020).

More recent examples of this transmission process are the emergences of CHIKV and ZIKV viruses in the Americas and consequently in French Guiana. Since its first identification in the early 1950s in Tanzania, the spread of CHIKV has been responsible for many large outbreaks in Africa, Asia, and the Pacific Islands (Robinson, 1955; Rougeron et al., 2015). While CHIKV transmission had never been documented before in the Americas (Coffey et al., 2014; Pialoux et al., 2007; Powers and Logue, 2007; Tsetsarkin et al., 2011), autochthonous cases were detected in December 2013 in the French 
overseas territory of Saint Martin, which led to the rapid spread and transmission of CHIKV in the Caribbean countries and the Americas, including French Guiana, within 9 months (Cassadou et al., 2014). Specifically, a few locally acquired cases of CHIKV were reported in February 2014. By June 2014, the epidemiological situation had evolved to moderate autochthonous transmission, epidemic clusters, and more extended transmission chains, which led local health authorities to launch an epidemic alert in September 2014. A total of 16,010 clinical cases were detected from December 2013 to November 2015 including 484 hospitalizations and two deaths (Santé Publique France, 2015).

ZIKV was considered an emergent virus with few sporadic cases reported in Africa and Asia until 2007, when a major epidemic occurred in Yap, Federated States of Micronesia (Duffy et al., 2009), followed by one in French Polynesia in 2013 (loos et al., 2014). Subsequently, ZIKV continued to spread in the Pacific region and emerged in South America in early 2015 (Musso, 2015; Petersen et al., 2016). The virus raised global attention due to its rapid spread since its first detection in May 2015 in Brazil to 50 other countries and territories in the Americas (Hoen et al., 2018; Sanchez, 2017). In French Guiana, the introduction of ZIKV from an imported case from Suriname was confirmed in early December 2015 (de Laval et al., 2016; Santé Publique France, 2016). In the month following this first warning, the epidemiological situation gradually evolved, as the number of autochthonous cases and clusters increased across the coastal strip. The epidemic alert was quickly launched in late January 2015 , for a total of 9,700 detected clinical cases.

Yellow fever (YF) is another well-known example of arboviral disease that has expanded its geographic range because of traveling hosts, vectors, and ease of shipping and transportation. The virus spread to the Americas upon the arrival of slave ships bearing both infected travelers and highly competent Ae. aegypti vectors. French Guiana is considered endemic for YF. Since 1967, YF vaccination is mandatory in French Guiana for all individuals older than 1 year of age. Since November 2016, after decades of silence, Brazilian authorities and scientists have reported an outbreak of YF associated with an exponential increase in the number of confirmed cases and deaths in humans in rural Brazilian areas, clearly reflecting a typical sylvatic transmission cycle occurring between forest mosquitoes and forest-dwelling non-human primates, with humans serving only as accidental hosts. Considering the large number of travelers moving through the Brazilian river border, this recent outbreak has raised particular concern that an urban transmission could occur in French Guiana, specifically for unvaccinated population subgroups, through the Ae. aegypti mosquitoes that are highly present in the territory. In this context, four sporadic and fatal cases of YF were reported in French Guiana 1 year apart, in unvaccinated migrant individuals, recently arrived in the territory by river routes and involved in activities in the forest environment (Sanna et al., 2018). These recent events confirm that 
sylvatic YF circulation could be active in this territory and highlight the importance of maintaining vaccine efforts and policies, particularly in cross-border areas connected by river routes (outside of vaccination control) to countries potentially lacking sufficient vaccination coverage.

Malaria is another example of a disease for which the epidemiological pattern is affected by population movements. Until the 1990s, French Guiana recorded nearly 5,000 cases of malaria each year; the most affected areas located along the Maroni and the Oyapock rivers, and impacting the Amerindian and Maroon populations (Douine et al., 2016; Musset et al. 2014). From 2006 onwards, malaria transmission dropped sharply in border countries, particularly Suriname, and then in French Guiana, as a result of rapid diagnostic tests followed by an effective treatment of cases (using artemisinin-containing drug combinations) and insecticide-treated net distribution programs. Over the past 5 years, the malaria endemy amounted to 200-600 cases per year, with contamination occurring mainly in the Oyapock catchment area, Upper Maroni sectors, and Interior (especially mining areas). These miners are working illegally and in poor health conditions. Almost $95 \%$ of them are of Brazilian origin, essentially from the poorest states of Brazil, i.e., Maranhão, Pará, and Amapá (Douine et al., 2018a). They have generally been working in this economic activity for a long time. During their career, they move from one mining site to another, within French Guiana or in foreign mining sites (Pommier de Santi et al., 2016). For logistical reasons or when they feel very bad, they may exit the deep forest and look for care in the French health centers or in bordering countries. As they are moving essentially between endemic areas, except for Maranhão state, they disperse malaria and maintain an active pool of parasites shared between French Guiana, Suriname, and the northern states of Brazil. Working deep within the forest, they also self-medicate with inappropriate medications or dosages, which can lead to the selection of resistant parasites (Douine et al., 2018b).

\section{Discussion}

French Guiana is hence a melting pot of environmental, bioecological, and socioeconomic drivers for old and new emerging diseases to develop and spread, potentially challenging the current diagnostic and therapeutic efforts made in the area. Recent advances have been made in French Guiana to better combat old and new emerging disease threats thanks to substantial funding and the reinforcement of the research workforce during the last two decades (Table 1). 
First, recent research and biomedical advances in this region have required the development of adequate analytic tools, both for diagnosis and epidemiology. The microbial diversity of wildlife in French Guiana is still largely unexplored (but see Salmier et al., 2016; Tirera et al., in prep), and the diversity of noninventoried pathogens for humans and animals may be huge. Novel diagnostic tools are now in routine use, including massive sequencing of full or partial DNA/RNA contents and a highthroughput serological approach. These have led to the recent discovery of new microbial forms that are potentially pathogenic for humans (e.g., Binetruy et al. 2020a, 2020b; Lavergne et al., 2015). However, despite all these methodological developments, we should not forget that the description of molecular sequences does not specify the existence of a disease risk if it is not demonstrated by appropriate experiments (Hosseini et al., 2017).

Second, high-resolution remote-sensing data and satellite imagery can help decipher spatial complexity and heterogeneity as observed in tropical biomes, when combined with cuttingedge analytical methods and validation through targeted field sampling. Mathematical modeling, combined with stage-stratified serological surveys, can be insightful and help reveal unsuspected transmission pathways of pathogens with low prevalence. Since ZVB pathogens circulate within complex spatial networks and highly diverse species communities, Ecological Niche Modeling (ENM) can be a game-changing methodology that makes it possible to identify local biotic (B), abiotic (A) and social and economic conditions such as spatial movement $(M)$ as main drivers of epidemiological transition. The overarching objectives of pathogeography and the BAM framework are to determine how the interactions among varying biotic (e.g., species competition, pathogen adaptation), abiotic (e.g., climate, topography), and dispersal (e.g., human movement, transcontinental transportation, geographical barriers) conditions and processes combine to shape the biogeographic and ecological conditions in infectious diseases through space and time. This allows scaling change to understand its role on disease emergence and patterns (Chavy et al., 2019a; de Thoisy et al., 2020), a major challenge for modern epidemiology (Ezenwa et al., 2015).

Third, French Guiana now constitutes one of the best-documented regions of the world, evidencing that ENSO has an effect on a set of different human infections. Both short-term, i.e., seasonal, and medium-term, i.e., the ENSO transition, phenomena, drive malaria, cutaneous leishmaniosis, dengue fever, and Buruli ulcer, an additional argument in favor of a climate effect on such disease systems. However, and even if regional climate variability tends to produce more frequent epidemic waves in French Guiana, it explains a minor part of disease incidence with less than $15 \%$ of the total number of human cases explained in this region. Overall, the intensity of disease amplitude and severity 
should be better explained by the interplay between human activities, demography, and socioeconomic conditions as well as pathogen properties.

Fourth, coarse-scale studies, as done generally with the climate-disease relationship (see above), tend to favor the importance of weather and climatic variables in explaining infectious disease presence and spatial distribution (Bhatt et al., 2013; Messina et al., 2016; Pigott et al., 2014). However, working at a regional spatial scale highlights the importance of the effect of the so-called Eltonian noise hypothesis (Chavy et al., 2019a), which assumes that local interactions (e.g., ecological networks), human activities, or microhabitat conditions (e.g., habitat alteration), required by a specific disease agent cycle to sustain itself, should not affect niche estimates at broader scales (see Figure 2). With the same set of human disease cases, we have been able to show that looking at the South American scale, weather and climate were the main predictors of leishmaniasis disease presence and geographical distribution, whereas at a finer scale, i.e., French Guiana, human activities at the interface between biodiversity, ecosystems, and land-use transformations were major forces for explaining leishmaniasis outbreaks and spread (Chavy et al., 2019a). Disease pattern explanations and determinants are therefore clearly scale-dependent, pinpointing the crucial need in modern epidemiological research to understand emerging disease processes at different spatiotemporal scales, without forgetting the most important one, which is definitely local, as a bridge scale level between molecular studies and global environmental approaches (Ezenwa et al., 2015).

Fifth, among biotic factors, habitat changes may disrupt host and vector species communities and ecological network food webs, and alter natural disease agent lifecycles. Zoonotic infections such as hantavirus disease may evidence a dilution effect in small mammal species-rich communities (Luis et al., 2018), although other infectious diseases such as Chagas are more prone to be contracted in both more and less species-rich habitats. Other diseases such as cutaneous leishmaniasis may show simultaneous dilution and amplification effects in space and time depending on the local composition and structure in host reservoir and vector species. In short, the biodiversity-disease relationship cannot be simplified by considering only biodiversity per se without taking into account the disease system specificities and their habitat conditions. Fieldwork, and particularly in large unexplored tropical regions, is still required before drawing hasty conclusions on the uniformity of a dilution effect as an ecosystem service to fight against new emerging disease risks (see García-Peña et al., 2016).

Sixth, our research on bat and rodent viromes clearly indicates that most viral families found on these neotropical mammals are acquired through food webs and foraging habits, habitat being a key driver of viral diversity. This finding is clearly indicative of a major misunderstanding in modern ani- 
mal virology on what is a true host reservoir and what is not. Food consumption and foraging are keys for understanding disease agent acquisition as important pathways, and research on highly pathogenic disease agents transmitted by bats on other continents, e.g., Ebola virus in Western and Central Africa, should better take into consideration these important components for disentangling the exact role played by giant bats on Ebola virus transmission, for instance.

Seventh, long-term observations of disease systems over the French Guiana region tend to suggest the existence of complex and focal ecological interactions of hosts, non-hosts, and vectors in these species-rich ecosystems. For example, human cases of leprosy are rare, but to our current knowledge the spatial distribution of Mycobacterium leprae, the bacillus causing leprosy, is also highly unlikely to be dispersed in armadillos, the putative reservoirs, contrary to the basic assumption that the bacterium could present a wide spatial distribution since it is nearly everywhere in forest ecosystems. Identifying these connections between hosts, vectors, and humans in both space and time is fundamental in order to better understand these complex ecological and evolutionary mosaics of hostpathogen interactions and their microscale evolutionary dynamics.

Eighth, as soon as abiotic (i.e., climatic) and biotic factors (i.e., biodiversity of hosts, vectors) are united to explain zoonotic and vector-borne disease transmission, other determinants are also paramount in the establishment and development of disease. Population demography and movements and at-risk behaviors are key drivers for explaining observed disease patterns in French Guiana. The strengthening of the epidemiological surveillance system conducted over the past two decades in the region has highlighted the critical role of international and regional transportation in outbreak epidemics linked to vector-borne diseases (dengue in 2012 and 2019, chikungunya in 2013, Zika in 2015). French Guiana is a land of migration where human movements, as well as the challenging economic situation and the strong increase of informal housing in slums in the vicinity of Cayenne and many other cities play a crucial role in disease emergence and spread, such as yellow fever and malaria.

Ninth, exhaustive knowledge of communities, ways of life, and pathogen flows across international land borders seems illusory in this region. Indeed, borders do not separate two territories, but are often traditional living spaces for human communities that can belong to the same ethnic groups. In that sense, epidemiological surveillance and prevention of epidemics and/or emergence should allow the neighboring countries to have a unified and shared vision of the epidemiological situation in such cross-border areas, by better developing transboundary cooperation and shared surveillance systems (Saldanha et al., 2020). Locally, living habits also condition the at-risk behaviors and disease patterns, 
pushing people towards the edges of favorable conditions and more risky areas. Traditional (e.g., hunting, fishing, agriculture) and extractive (e.g., gold mining, timber production) activities and settlements at forest edges are clearly exposure factors to Amazonian toxoplasmosis, cutaneous leishmaniasis, leptospirosis, $Q$ fever, and malaria. Also, half a century of monitoring cutaneous leishmaniasis in French Guiana has highlighted how more at-risk populations and behaviors are linked to the socioeconomic transition in this region, with target populations splitting from agriculture and hunters in the past decades to gold miners today.

Tenth, one important finding delivered in this synthesis is that the classic, academic picture of the disease lifecycle as taught in university courses has to be challenged, since new ecological settings, e.g., greater contact between humans and wildlife, natural habitat alteration, and new disease hazards may expose more humans to animal infections, i.e., zoonosis, or to environmental pathogens, i.e., sapronosis, while bringing more animals into contact with human infections, e.g., contagious diseases, reverse zoonosis. As illustrated by the case of South American malaria, it then becomes difficult to distinguish which came first: the egg, i.e., the human host reservoir, and the chicken, i.e., the monkey target host (Guégan et al., 2020). In light of the tremendous work done on different multi-host-disease systems in French Guiana, it now seems necessary to reconsider the disease ecology of many other ZVB human infections within the context of a changing global environment.

\section{Conclusion}

Woolhouse and Gowtage-Sequeria (2005) ranked the different major drivers of emerging and reemerging pathogens in humans globally, based on 177 different pathogens, and counting pathogen numbers per corresponding driver. This work was highly influential during the following years by positioning the importance and respective role of the different determinants in disease emergence and reemergence, and potentially in subsequent research and health care policy strategies implemented to elucidate and control disease emergence processes. Interestingly, no research has done the same at a finer scale. Benefitting from our research community experience in French Guiana (the present work), a questionnaire was sent to the different coauthors of this review article during the writing process, and before reaching the final version of the manuscript, in order not to be influenced by its reading. As illustrated in Table 2, the three drivers ranked as being the first by Woolhouse and Gowtage-Sequeria, i.e., changes in land use or agricultural practices, changes in human demographics and societies, and poor population health, are also those ranked as the first three by 
our research consortium for the local French Guiana context. However, two main differences can be observed between the two studies: international travel is ranked 4th in our present survey and 7th in the global study, due to the specific context of French Guiana for which transcontinental transportation is vital for the local economy; failure of public health programs is ranked 6th (versus 8th globally) because French Guiana has suffered from several major epidemics during the last few decades, thus challenging public health programs and health care, and this has become a top priority for the French government; climate change is ranked 7th (against 10th globally) notably because French Guiana is experiencing the ENSO phenomenon with real observations that can be made by people in this region; and hospitals and medical procedures ranked 10th (versus 4th globally), notably because French Guiana is endowed with good hospital quality and very good health care in comparison to other countries on the continent.

In conclusion, as pointed out by this final analysis, human demography, poor health conditions, and landscape alteration through human activities such as agriculture development and resource extraction constitute the current local conditions that may favor new emerging and reemerging pathogens and their spread in the future. French Guiana is combining these three important conditions for disease emergence to occur, and we strongly recommend a transdisciplinary, coordinated surveillance of these important phenomena. Additionally, we also invite other research consortia worldwide to revisit and adapt the same kind of comparison of local vs. global drivers, as don in the present review, to better capture the local conditions of disease emergence in order to more appropriately adapt health care programs. Even if our local societies are today facing major global changes, we definitely need to better understand the local contexts and conditions that may help disease emergence and spread, and then make local resilience a priority in future national and international agendas.

\section{Acknowledgements}

This work has benefited from three "Investissement d'Avenir" grants managed by Agence Nationale de la Recherche (CEBA: ANR-10-LABX-25-01; TULIP: ANR-10-LABX-0041; DRIIHM: ANR-11-LABX0010). The two lead coauthors received European funding through the European Regional Development Fund Operational Program FEDER RESERVOIRS Project (BdT) and a US NSF-NIH (NSF\#1911457) Ecology of infectious diseases award (J-FG). J-FG is also supported by IRD, INRAE, and Université of Montpellier. OD thanks l'Office français de la biodiversité, le Groupe d'Étude et de Protection des Oiseaux en Guyane (GEPOG), la Direction de l'Alimentation, de l'Agriculture et de la Forêt de Guyane 
(DAAF). AL acknowledges European funding through the European Regional Development Fund Operational Program FEDER RESERVOIRS, CAROLLIA, EFAG and VIRUSES projects. LM is supported by European funding through the European Regional Development Fund Operational Program FEDER ELIMALAR project and Santé publique France as the National Reference Center for Malaria. PQ thanks Publique France / Cire Guyane, CNR sur les arboviroses, CNR du paludisme. EH and ID acknowledge European funding through the European Regional Development Fund Operational Program FEDER CONTROLE Projet, the French Guiana Regional Council and the Air Liquide Foundation. SB is supported by the French Army (Grant LR607e). ER is grateful for European funding through the European Regional Development Fund Operational Program FEDER OSE-Guyamapa project, the French Embassy in Brazil, the Guyamazon program ("GAPAM-Sentinela" project), CNES, and the Bill and Melinda Gates Foundation.

\section{Declaration of interests}

\The authors declare that they have no known competing financial interests or personal relationships that could have appeared to influence the work reported in this paper.

\section{References}

Adde, A., Roucou, P., Mangeas, M., Ardillon, V., Desenclos, J-C., Rousset, D., Girod, R., Briolant, S., Quenel, P., Flamand, C., 2016a. Predicting. Dengue fever outbreaks in French Guiana using climate indicators. PLoS Negl. Trop. Dis., 10, e0004681. https:// doi.org/10.1371/journal.pntd.0004681 Adde, A., Dusfour, I., Roux, E., Girod R, Briolant, S., 2016b. Anopheles fauna of coastal Cayenne, French Guiana: modelling and mapping of species presence using remotely sensed land cover data. Mem. Inst. Oswaldo Cruz, 111, 750-756. https://doi.org/10.1590/0074-02760160272. Adde, A., Roux, E., Mangeas, M., Dessay, N., Nacher, M., Dusfour, I., Girod, D., Brioland, S., 2016c. Dynamical mapping of Anopheles darlingi densities in a residual malaria transmission area of French Guiana by using remote sensing and meteorological data. PLoS One, 11, e0164685. https://doi.org/10.1371/journal.pone.0164685 Allan, B.F., Keesing, F., Ostfeld, R.S., 2003. Effect of forest fragmentation on Lyme disease risk. Cons. Biol., 17, 267-272. https://doi.org/10.1046/j.1523-1739.2003.01260.x

Allen, T., Murray, K.A., Zambrana-Torrelio, C., Morse, S.S., Rondinini, C., Di Marco, M., Bretit, N., Olival, K.J., Daszak, P., 2017. Global hotspots and correlates of emerging zoonotic diseases. Nat. Comm., 24, 1124. https://doi.org/ 10.1038/s41467-017-00923-8.

AUDEG, 2019. Observatoire foncier de la Guyane. Panorama\#4 : Atlas des tissus urbains. 
Audoux, L., Mallemanche, C., Prévot, P., 2020. Une pauvreté marquée dans les DOM,notamment en Guyane et à Mayotte. INSEE Première, 1804.

Aznar, C., La Ruche, G., Laventure, S., Carme, B., Liegeard. P., Hontebeyrie, M., 2004. Seroprevalence of Trypanosoma cruzi infection in French Guiana. Mem. Inst. Oswaldo Cruz, 99: 805808. http://dx.doi.org/10.1590/S0074-02762004000800004.

Ballère, M., Bouvet, A., Mermoz, S., Le Toan, T., Koleck, T., Bedeau, C., André, M., Forestier, E., Frison, P.L., Lardeux, C., 2021. SAR data for tropical forest disturbance alerts in French Guiana: Benefit over optical imagery. Remote Sensing Envir., 252: 112159.

https://doi.org/10.1016/j.rse.2020.112159

Banu, S., Hu, W., Hurst, C., Tong, S. 2011. Dengue transmission in the Asia-Pacific region: impact of climate change and socio-environmental factors. Trop. Med. Int. Health, 16, 598-607.

https://doi.org/10.1111/j.1365-3156.2011.02734.x

Basset, D., Pratlong, F., Ravel, C., Puechberty, J., Dereure, J., Dedet, J. 2001. Les leishmanioses déclarées en France en 1999. Bull. Épidémiol. Hebd., 5, 19-20.

Bérenger, J.M., Pluot-Sigwalt, D., Pages, F., Blanchet, D., Aznar, C., 2009. The triatominae species of French Guiana (Heteroptera: Reduviidae). Mem. Inst. Oswaldo Cruz, 104, 1111-1116.

https://doi.org/10.1590/S0074-02762009000800007

Berger, F., Flamand, C., Musset, L., Djossou, F., Rosine, J., Sanquer, M.A., Dusfour, I., Legrand, E., Ardillon, V., Rabarison, P., Grenier C., Girod, R., 2012. Investigation of a sudden Malaria outbreak in the isolated amazonian village of Saül, French Guiana, January-April 2009. Am. J. Trop. Med. Hyg., 86, 591-597. https://doi.org/10.4269/ajtmh.2012.11-0582

Bergner, L.M., Orton, R.J., Benavides, J.A., Becker, D.J., Tello, C., Biek, R., Streicker, D.G., 2020. Demographic and environmental drivers of metagenomic viral diversity in vampire bats. Mol. Ecol., 29, 26-39. https://doi.org/10.1111/mec.15250

Bhatt, S., Gething, PW., Brady, O.J., Messina, J.P., Farlow, A.W., Moyes, C.L,, Drake, J.M., Brownstein, J.S., Hoen, A.G., Sankoh, O., Myers, M.F., George, D.B., Jaenisch, T., Wint, G.R., Simmons, C.P., Scott, T.W., Farrar, J.J., Hay, SI., 2013. The global distribution and burden of dengue. Nature 496, 504-507. https://doi.org/10.1038/nature12060

Binetruy, F., Dupraz, M., Buysse, M., Duron, O., 2019. Surface sterilization methods impact measures of internal microbial diversity in ticks. Parasites Vectors, 12, 268. https://doi.org/10.1186/s13071019-3517-5

Binetruy, F., Dupraz, M., Buysse, M., Duron, O., 2020a. Novel Rickettsia genotypes in ticks in French Guiana, South America. Sci. Rep., 10, 2537. https://doi.org/10.1038/s41598-020-59488-0

Binetruy, F., Garnier, S., Boulanger, N., Talagrand-Reboul, E., Loire, E., Faivre, B., Noël, V., Buysse, M., Duron, O., 2020b. A novel Borrelia species, intermediate between Lyme disease and relapsing fever 
groups, in neotropical passerine-associated ticks. Sci. Rep., 10, 10596.

https://doi.org/10.1038/s41598-020-66828-7

Binetruy, F., Buysse, M., Lejarre, Q., Barosi, R., Villa, M., Rahola, N., Paupy, C., Ayala, D., Duron, O., 2020c. Microbial community structure reveals instability of nutritional symbiosis during the evolutionary radiation of Amblyomma ticks. Mol. Ecol., 29, 1016-1029.

https://doi.org/10.1111/mec.15373

Blaizot, R., Nabet, C., Laghoe, L., Faivre, B., Escotte-Binet, S., Djossou, F., Mosnier, E., Henaff, F., Blanchet, D., Mercier, A., Dardé, M.L., Villena, I., Demar, M., 2020. Outbreak of Amazonian Toxoplasmosis: a One Health investigation in a remote amerindian community. Front. Cell. Infect. Microbiol., 10: 401. https://doi.org/ 10.3389/fcimb.2020.00401

Bolatti, E.M., Zorec, T.M., Montani, E., Hošnjak, L., Chouhy, D., Casal, P.E., Barquez, R.M., Poljak, M., Giri, A.A., 2020. A preliminary study of the virome of the South American Free-Tailed Bats (Tadarida brasiliensis) and identification of two novel mammalian viruses. Viruses, 12, 422.

https://doi.org/10.3390/v12040422

Bonnet, S., Binetruy. F., Hernandez. A., Duron. O., 2017. The tick microbiome: why non-pathogenic microorganisms matter in tick biology and pathogen transmission. Front. Cell. Infect. Microbiol., 7, 236. https://doi.org/10.3389/fcimb.2017.00236

Bouma, M.J., Dye, C. 1997. Cycles of malaria associated with El Niño in Venezuela. JAMA, 278, 17721774. https://doi.org/10.1001/jama.1997.03550210070041

Bouma, M.J., Poveda, G., Rojas, W., Chavasse, D., Quinones, M., Cox, J., Patz, J., 1997. Predicting high-risk years for malaria in Colombia using parameters of El Niño Southern Oscillation. Trop. Med. IntHealth, 2, 1122-1127. https://doi.org/10.1046/j.1365-3156.1997.d01-210.x

Bouma, M.J., Sondorp, H.E., van der Kaay, H.J. 1994. Climate change and periodic epidemic malaria. Lancet, 343, 1440. https://doi.org/10.1016/s0140-6736(94)92569-0

Bovolo, C.I., Pereira, R., Parkin, G., Kilsby, C., Wagner, T., 2012. Fine-scale regional climate patterns in the Guianas, tropical South America, based on observations and reanalysis data. Int. J. climatol., 32, 1665-1689. https://doi.org/10.1002/joc.2387

Briolant, S., de Melo Costa, M., Nguyen, C., Dusfour, I., de Santi, V. P., Almeras, L. 2020. Identification of French Guiana anopheline mosquitoes by MALDI-TOF MS profiling using protein signatures from two body parts. PLoS One, 15: e0234098. https://doi.org/10.1371/journal.pone.0234098 Browne, A.J., Guerra, C.A., Alves, R.V., da Costa, V.M, Wilson, A.L., Pigott, D.M., Hay, S.I., Lindsay, S.W., Golding, N., Moyes, C.L., 2017. The contemporary distribution of Trypanosoma cruzi infection in humans, alternative hosts and vectors. Sci. Data, 4, 170050. https://doi.org/10.1038/sdata.2017.50. Cambrézy, L., 2015. Immigration et statistiques en Guyane. Une opacité contraire aux principes de bonne gouvernance. Autrepart, 74-75, 193-214. 
Campbell, K.M., Haldeman, K., Lehnig, C., Munayco, C.V., Halsey, E.S., Laguna-Torres, V.A., Yagui, M., Morrison, A.C., Lin, C.D., Scott, T.W., 2015. Weather regulates location, timing, and intensity of dengue virus transmission between humans and mosquitoes. PLoS Negl. Trop. Dis., 9, e0003957.

https://doi.org/ 10.1371/journal.pntd.0003957

Cardenas, R., Sandoval, C.M., Rodriguez-Morales, A.J., Franco-Paredes, C. 2006. Impact of climate variability in the occurrence of leishmaniasis in northeastern Colombia. Am. J. Trop. Med. Hyg., 75, 273-277. https://doi.org/10.4269/ajtmh.2006.75.273

Cardona-Castro, N., Beltrán, J.C., Ortiz-Bernal, A., Vissa, V., 2009. Detection of Mycobacterium leprae DNA in nine-banded armadillos (Dasypus novemcinctus) from the Andean region of Colombia. Lepr. Rev., 80, 424-31.

Carme, B., Demar, M., Ajzenberg, D., \& Dardé, M. L. 2009. Severe acquired toxoplasmosis caused by wild cycle of Toxoplasma gondii, French Guiana. Emerg. Infect. Dis., 15, 656. https://doi.org/ 10.3201/eid1504.081306

Cassadou, S., Boucau, S Petit-Sinturel, M., Huc, P., Leparc-Goffart, I., Ledrans, M., 2014. Emergence of chikungunya fever on the French side of Saint Martin Island, October to December 2013. Eurosurveillance, 19, 20752. https://doi.org/10.2807/1560-7917.ES2014.19.13.20752

Catry, T., Li, Z., Roux, E., Herbreteau, V., Gurgel, H., Mangeas, M., Seyler, F., Dessay, N., 2018. Wetlands and malaria in the Amazon: guidelines for the use of synthetic aperture Radar Remote-Sensing. Int. J. Environ. Res. Public Health, 15, 468. https://doi.org/10.3390/ijerph15030468

Cazelles, B., Chave, M., McMichael, A.J., Hales, S., 2005. Nonstationary influence of El Niño on the synchronous Dengue epidemics in Thailand. PLoS Med., 2, e106: 313-318.

https://doi.org/10.1371/journal.pmed.0020106

Chavy, A., Ferreira Dales Nava, A., Luiz Bessa Luz, S., Ramirez, J.D., Herrera, G., Vasconcelos dos Santos, T., Ginouves, M., Demar, M., Prévot, G., Guégan, J.F., de Thoisy, B. 2019a. Ecological niche modelling for predicting the risk of cutaneous leishmaniasis in the Neotropical moist forest biome. PLoS Negl. Trop. Dis., 13, e0007629. https://doi.org/10.1371/journal.pntd.0007629

Chavy, A., Nabet, C., Normand, A.C., Kocher, A., Ginouves, M., Prévot, G., Vasconcelos dos Santos, T., Demar, M., Piarroux R., de Thoisy, B., 2019b. Identification of French Guiana sand flies using MALDITOF mass spectrometry with a new mass spectra library. PLoS Negl. Trop. Dis., 13, e0007031. https://doi.org/10.1371/journal.pntd.0007031

Chavy, A., Kocher, A., Tirera S., Huguin, M., Leroy, C., Prévot, G., Guégan, J.F., de Thoisy, B. Regional scale ecological drivers of sandfly communities in French Guian. In prep.

Chippaux, J.P., Pajot, F.X., Barbier, D., 1984. La leishmaniose en Guyane française. V. Note complémentaire sur l'écologie du vecteur dans le village forestier de Cacao. Cahiers-ORSTOM. Entomol. Med. Parasitol., 22, 213-218. 
Christen, J.R., Edouard, S., Lamour, T., Martinez, E., Rousseau, C., de Laval, F., Catzeflis, F., Djossou, F., Raoult, D., Pommier de Santi, V., Epelboin, L., 2020. Capybara and brush cutter involvement in Q Fever outbreak in remote area of Amazon rainforest, French Guiana, 2014. Emerg Infect Dis., 26, 993-7. https://doi.org/ 10.3201/eid2605.190242

Coffey, L.L., Failloux, A.B., Weaver, S.C., 2014. Chikungunya virus-vector interactions. Viruses 6, 46284663. https://doi.org/10.3390/v6114628

Combe, M., Gozlan, R.E., Jagadesh, S., Velvin, C.J., Ruffine, R., Demar, M.P., Couppie, P., Djossou, F., Nacher, M., Epelboin, L. 2019. Comparison of Mycobacterium ulcerans (Buruli ulcer) and Leptospira sp. (Leptospirosis) dynamics in urban and rural settings. PLoS Negl Trop Dis., 13, e0007074. https://doi.org/10.1371/journal.pntd.0007074 Cucunubá, Z., Nouvellet, P., Conteh, L., Vera, M.J., Anguo, V.M., Dib, J.C., Parra-Henao, G.J., Basáñez, M.G., 2017. Modelling historical changes in the force-of-infection of Chagas disease to inform control and elimination programmes: application in Colombia. BMJ Global Health, 2.

https://doi.org/10.1136/bmjgh-2017-000345

Darie, H., Deniau, M., Pratlong, F., Lanotte, G., Talarmin, A., Millet, P., Houin, R., Dedet, J.P., 1995. Cutaneous leishmaniasis of humans due to Leishmania (Viannia) naiffi outside Brazil. Trans. R. Soc. Trop. Med. Hyg., 89, 476-477. https://doi.org/ 10.1016/0035-9203(95)90071-3 da Rosa, C.A., Ribeiro, B.R., Bejarano, V., Puertas, F.H., Bocchiglieri, A., dos Santos Barbosa, A.L., de Souza, A.C., 2020. Neotropical alien mammals: a data set of occurrence and abundance of alien mammals in the Neotropics. Ecology, 101. https://doi.org/10.1002/ecy.3115 Davoust, B., Marie, J.L., Pommier de Santi, V., Berenger, J.M., Edouard, S., Raoult, D., 2014. Threetoed sloth as putative reservoir of Coxiella burnetii, Cayenne, French Guiana. Emerg. Infect. Dis., 20, 1760-1761. https://doi.org/ 10.3201/eid2010.140694

Dedet, J.P., Pradinaud, R., Gay, F., 1989. Epidemiological aspects of human cutaneous leishmaniasis in French Guiana. Trans Roy. Soc. Trop. Med. Hyg., 83, 616-620.

de Laval, F., Matheus, S., Maquart, M., Yvrard, E., Barthes, N., Combes, C., Rousset, D., LeparcGoffart, I., Briolant, S. 2016. Prospective Zika virus disease cohort: systematic screening. Lancet, 27, 868. https://doi.org/10.1016/S0140-6736(16)31429-5

Demar, M., Ajzenberg, D., Maubon, D., Djossou, F., Panchoe, D., Punwasi, W., Valery, N., Peneau, C., Daigre, J.L., Aznar, C., Cottrelle, B., Terzan, L., Dardé, M.L., Carme, B., 2007. Fatal outbreak of human toxoplasmosis along the Maroni River: epidemiological, clinical, and parasitological aspects. Clin. Infect. Dis., 45, e88-95. https://doi.org/10.1086/521246

Demar, M., Ajzenberg, D., Serrurier, B., Dardé, M.L., M.L., Carme, B., 2008. Atypical Toxoplasma gondii strain from a free-living jaguar (Panthera onca) in French Guiana. Am. J. Trop. Med. Hyg., 78, 195-197. https://doi.org/10.4269/ajtmh.2008.78.195 
Demar, M., Hommel, D., Djossou, F., Peneau, C., Boukhari, R., Louvel, D., Bourbigot, A.M., Nasser, V., Ajzenberg, D., Dardé, M.L., Carme, B. 2012. Acute toxoplasmoses in immunocompetent patients hospitalized in an intensive care unit in French Guiana. Clin. Microbiol. Infection, 18, e221-E231. https://doi.org/10.1111/j.1469-0691.2011.03648.x

Descloux, E., Mangeas, M., Menkès, C.E., Lengaigne, M., Leroy, A., Tehei, T., Guillaumont, L., Teurlai, M., Gourinat, A.C., Benzler, J., Pfannstiel, A., Grangeon, J.P., Degallier, N., De Lamballerie, X., 2012. Climate-based models for understanding and forecasting dengue epidemics. PLoS Negl. Trop. Dis., 6: e1470. https://doi.org/10.1371/journal.pntd.0001470

de Thoisy, B., Demar, M., Aznar, C., Carme, B., 2003. Ecologic correlates of Toxoplasma gondii exposure in free-ranging neotropical mammals. J. Wild. Dis., 39, 456-459. https://doi.org/10.7589/00903558-39.2.456

de Thoisy, B., Richard-Hansen, C., Goguillon, B., Joubert, P., Obstancias, J., Winterton, P., Brosse, S. 2010. Rapid evaluation of threats to biodiversity: human footprint score and large vertebrate species responses in French Guiana. Biodiv. Conserv., 19, 1567-1584. https://doi.org/10.1007/s10531-0109787-z

de Thoisy, B., Lacoste, V., Germain, A., Muñoz-Jordán, J., Colón, C., Mauffrey, J.F., Delaval, M., Catzeflis, F., Kazanji, M., Matheus, S., Dussart, P., Setién, A.A., Morvan, J., Deparis, X., Lavergne, A., 2009. Dengue infection in neotropical forest mammals. Vector Borne Zoonotic Dis., 9, 157-170.

https://doi.org/10.1089/vbz.2007.0280

de Thoisy, B., Matheus, S., Catzeflis, F., Clément, L., Barrioz, S., Guidez, A., Donato, D., Cornu, J-F., Brunaux, O., Guitet, S., Lacoste, V., Lavergne, A., 2014. Maripa hantavirus in French Guiana: phylogenetic position and predicted spatial distribution of rodent hosts. Am. J. Trop. Med. Hyg., 90, 988-992. https://doi.org/10.4269/ajtmh.13-0257

de Thoisy, B., Bourhy, H., Delaval, M., Pontier, D., Dacheux, L., Darcissac, E., Donato, D., Guidez A, Larrous, F., Lavenir, E., Salmier, A., Lacoste, V., Lavergne, A., 2016. Bioecological drivers of Rabies virus circulation in a neotropical bat community. PLoS Negl. Trop. Dis., 10, e0004378.

https://doi.org/10.1371/journal.pntd.0004378

de Thoisy, B., Silva, N.I.O., Sacchetto, L., de Souza Trindade. G., Drumond, B.P., 2020. Spatial epidemiology of yellow fever: Identification of determinants of the 2016-2018 epidemics and at-risk areas in Brazil. Plos Negl. Trop. Dis., 14, e0008691. https://doi.org/10.1371/journal.pntd.0008691

Dezécache, C., Faure, E., Gond, V., Salles, J. M., Vieilledent, G., Hérault, B., 2017. Gold-rush in a forested El Dorado: deforestation leakages and the need for regional cooperation. Env. Res. Letters, 12, 034013. https://doi.org/10.1088/1748-9326/aa6082

Dobson, A.D., 2004. Population dynamics of pathogens with multiple host species. Am. Nat., 164 Suppl, S64--S78. https://doi.org/10.1086/424681 
Douine, M., Musset, L., Corlin, F., Pelleau, S., Pasquier, J., Mutricy, L., Adenis, A., Djossou, F., Brousse, P., Perotti, F., Hiwat, H., Vreden, S., Demar, M., Nacher, M., 2016. Prevalence of Plasmodium spp. in illegal gold miners in French Guiana in 2015: a hidden but critical malaria reservoir. Malar. J., 15, 315. https://doi.org/10.1186/s12936-016-1367-6

Douine, M., Mosnier, E., Le Hingrat, Q., Charpentier, C., Corlin, F., Hureau, L., Adenis, A., Lazrek, Y., Niemetsky, F., Aucouturier, A.L., Demar, M., Musset, L., Nacher, M. 2018. Illegal gold miners in French Guiana: a neglected population with poor health. BMC Public Health, 18, 1-10. https://doi.org/10.1186/s12889-017-4557-4

Douine, M., Lazrek, Y., Blanchet, D., Pelleau, S., Chanlin, R., Corlin, F., Hureau, L., Volney, B., Hiwat, H., Vreden, S., Djossou, F., Demar, M., Nacher, M., Musset. L., 2018. Predictors of antimalarial selfmedication in illegal gold miners in French Guiana: a pathway towards artemisinin resistance. J. Antimicrob. Chemother., 73, 231-239. https://doi.org/10.1093/jac/dkx343

Douine, M., Sanna, A., Galindo, M., Musset, L., Pommier de Santi, V., Marchesini, P., Magalhes, E.D., Suares-Mutis, M., Hiwat, H., Nacher, M., Vreden, S., Garancher, L., 2018c. Malakit: an innovative pilot project to self-diagnose and self-treat malaria among illegal gold miners in the Guiana Shield. Malar J., 17, 158. https://doi.org/10.1186/s12936-018-2306-5

Duffy, M.R., Chen, T.H., Hancock, W.T., Powers, A.M., Kool, J.L., Lanciotti, R.S., Pretrick, M., Marfel, M., Holzbauer, S., Dubray, C., Guillaumot, L., Griggs, A., Bel, M., Lambert, AJ., Laven, J., Kosoy, O., Panella, A., Biggerstaff, B.J., Fischer, M., Hayes, E.B., 2009. Zika virus outbreak on Yap Island, Federated States of Micronesia. N. Engl. J. Med., 360, 2536-2543. https://doi.org/

\subsection{6/NEJMoa0805715}

Duron, O., Gottlieb, Y., 2020. Convergence of nutritional symbioses in obligate blood feeders. Trends Parasitol., 36, 816-825.

Dusfour, I., Zorrilla, P., Guidez, A., Issaly, J., Girod, R., Guillaumot, L., Robello, C., Strode, C. 2015. Deltamethrin resistance mechanisms in Aedes aegypti populations from three French Overseas Territories worldwide. PLoS Negl. Trop. Dis., 9, e0004226. https://doi.org/10.1371/journal.pntd.0004226 Ecker, A., Lehane, A.M., Clain, J., Fidock, D.A., 2012. PfCRT and its role in antimalarial drug resistance. Trends Parasitol., 28, 504-514. https://doi.org/10.1016/j.pt.2012.08.002

Edouard, S., Mahamat, A., Demar, M., Abboud, P., Djossou, F., Raoult, D., 2014. Comparison between emerging Q fever in French Guiana and endemic Q fever in Marseille, France. Am. J. Trop. Med. Hyg., 90, 915-919. https://doi.org/10.4269/ajtmh.13-0164

Eldin, C., Perreal, C., Mahamat, A., Djossou, F., Edouard, S., Raoult, D. 2015. Antibiotic susceptibility determination for six strains of Coxiella burnetii MST 17 from Cayenne, French Guiana. Int. J. Antimicrob. Agents, 46, 600-602 
Eldin, C., Melenotte, C., Mediannikov, O., Ghigo, E., Million, M., Edouard, S., Mege, J.L., Maurin, M., Raoult, D., 2017. From Q Fever to Coxiella burnetii infection: a paradigm change. Clin. Microbiol. Rev., 30, 115-190.

Epelboin, L., Chroboczek, T., Mosnier, E., Abboud, P., Adenis, A., Blanchet, D., Demar, P., Guiraud, N., Mahamat, A., Aznar, C., Nacher, M., Couppié, P., Carme B., Djossou, F., 2016. L'infectiologie en Guyane : le dernier bastion de la médecine tropicale française. Lett. Infect., 31.

Epelboin, L., Nacher, M., Mahamat, A., Pommier de Santi, V., Berlioz-Arthaud, A., Eldin, C., Abboud, P., Briolant, S., Mosnier, E., Mendonca Gomes, M.S., Vreden, S.G., Pierre-Demar, M., Lacerda, M., Raoult, D., Sampaio de Lemos, E.R., Djossou F., 2016. Q Fever in French Guiana: tip of the Iceberg or epidemiological exception? PLoS Negl. Trop. Dis., 10, e0004598.

https://doi.org/10.1371/journal.pntd.0004598

Epelboin, L., Mahamat, A., Bonifay, T., Demar, M., Abboud, P., Walter, G., Drogoul, A.S., BerliozArthaud, A., Nacher, M., Raoult, D., Djossou F, Eldin C., 2020. Q fever among community-acquired pneumonia in French Guiana: still the highest prevalence in the world. Case control study 2008-2012 and comprehensive review of the literature. Travel Med. Infect. Dis., In press.

Epelboin, Y., Chaney, S.C., Guidez, A., Habchi-Hanriot, N., Talaga, S., Wang, L., Dusfour, I., 2018. Successes and failures of sixty years of vector control in French Guiana: what is the next step? Mem. Inst. Oswaldo Cruz 113, e170398. https://doi.org/10.1590/0074-02760170398 Epelboin, Y., Talaga, S., Epelboin. L., Dusfour, I., 2017. Zika virus: An updated review of competent or naturally infected mosquitoes. PLoS Negl. Trop. Dis. ,11, e0005933.

https://doi.org/10.1371/journal.pntd.0005933

Ezenwa, V.O., Prieur-Richard, A.H., Roche B., Bailly, X., Becquart, P. , García-Peña, G.E., Hosseini, P.R., Keesing, F., Rizzoli, A., Suzán, G.A., Vignuzzi, M., Vittecoq, M., Mills, J.N., Guégan J.F., 2015. Interdisciplinarity and infectious diseases: an Ebola case study. PLoS Pathogens, 11, e1004992.

https://doi.org/10.1371/journal.ppat.1004992

Fahsbender, E., Charlys da-Costa, A., Elise Gill D., Augusto de Padua Milagres, F., Brustulin, R., Julio Costa Monteiro, F., Octavio da Silva Rego, M., Soares D'Athaide Ribeiro, E., Cerdeira Sabino, E., Delwart, E., 2020. Plasma virome of 781 Brazilians with unexplained symptoms of arbovirus infection include a novel parvovirus and densovirus. PLoS One, 15, e0229993.

https://doi.org/10.1371/journal.pone.0229993

Falkowski, M., JahnOyac, A., Odonne, G., Flora, C., Estevez, Y., Touré, S., Boulogne, I., Robinson, J.C., Béreau, D., Petit, P., Azam, D., Coke, M., Issaly., J, Gaborit, P., Stien, D., Eparvier, V., Dusfour, I., Houël, E., 2020. Towards the optimization of botanical insecticides research: Aedes aegypti larvicidal natural products in French Guiana. Acta Trop., 201, 105179.

https://doi.org/10.1016/j.actatropica.2019.105179 
Fandeur, T., Volney, B., Peneau, C., de Thoisy, B., 2000. Monkeys of the rainforest in French Guiana are natural reservoirs for $P$. brasilianum/P. malariae malaria. Parasitology, 120, 11-21.

https://doi.org/10.4081/gh.2014.12

Feliciangeli, M., Rabinovich, J., 1998. Abundance of Lutzomyia ovallesi but not Lu. gomezi (Diptera: Psychodidae) correlated with cutaneous leishmaniasis incidence in north-central Venezuela. Med. Vet. Entomol ., 12, 121-131. https://doi.org/10.1046/j.1365-2915.1998.00072.x Ferreira, M.C. 2014. Geographical distribution of the association between El Niño south oscillation and dengue fever in the Americas: a continental analysis using geographical information systembased techniques. Geospat. Health 9, 141-151. https://doi.org/10.4081/gh.2014.12

Flamand, C., Fabregue, M., Bringay, S., Ardillon, V., Quénel, P., Desenclos, J.C., Teisseire, M. ,2014. Mining local climate data to assess spatiotemporal dengue fever epidemic patterns in French Guiana J. Am. Med. Inform. Assoc., 21, e232-e240. https://doi.org/10.1136/amiajnl-2013-002348

Flamand, C., Bailly, S., Fritzell, C., Berthelot, L., Vanhomwegen, J., Salje, H., Paireau, J., Matheus, S., Enfissi A., Fernandes-Pellerin, S., Djossou, F., Linares, S., Carod, J.F., Kazanji, M., Manuguerra, J.C., Cauchemez S., Rousset D., 2019. Impact of Zika virus emergence in French Guiana: a large generalpopulation seroprevalence survey. J. Infect. Dis. 220, 1915-1925.

https://doi.org/10.1093/infdis/jiz396

Floch, H., 1954. Leishmania tropica guyanensis n.sp., pathogenic agent of Guyanese and Central American cutaneous leishmaniasis. Bull. Soc. Pathol. Exot., 47, 784-787.

Flores-Ferrer, A., Waleckx, E., Rascalou, G., Dumonteil, E., Gourbière, S. 2019. Trypanosoma cruzi transmission dynamics in a synanthropic and domesticated host community. PLoS Negl. Trop. Dis., 13, e0007902. https://doi.org/10.1371/journal. pntd.0007902

Fonseca-González, I., Quiñones, M.L., McAllister, J., Brogdon, W.G. 2009. Mixed-function oxidases and esterases associated with cross-resistance between DDT and lambda-cyhalothrin in Anopheles darlingi Root 1926 populations from Colombia. Mem. Inst. Oswaldo Cruz, 104, 18-26.

https://dx.doi.org/10.1590/S0074-02762009000100003

Franke, C.R., Ziller, M., Staubach, C., Latif, M., 2002. Impact of the El Niño/Southern Oscillation on visceral leishmaniasis, Brazil. Emerg. Infect. Dis., 8, 914-917. https://doi.org/10.3201/eid0809.010523 Franklinos, L.H.V, Jones, K.E., Redding, D.W., Abubakar, I., 2019. The effect of global change on mosquito-borne disease. Lancet Infect. Dis., 19: e302. https:// doi.org/10.1016/S1473-3099(19)30161-6 Gagnon, A.S, Bush, A.B, Smoyer-Tomic, K.E, 2001. Dengue epidemics and the El Niño southern oscillation. Clim. Res., 19, 35-43. https://doi.org/ doi:10.3354/cr019035 Gagnon, A.S., Smoyer-Tomic, K.E., Bush, A.B., 2002. The El Niño southern oscillation and malaria epidemics in South America. Int. J. Biometeorol., 46, 81-89. https://doi.org/10.1007/s00484-001-0119-6 
Galal, L., Hamidović, A., Dardé, M.L., Mercier, M., 2019. Diversity of Toxoplasma gondii strains at the global level and its determinants. Food Waterborne Parasitol., 15, e00052.

https://doi.org/10.1016/j.fawpar.2019.e00052

Garchitorena, A., Ngonghala, CN.., Landier, J., Texier, G., Landier, J., Eyangoh, S., Bonds, M., Guégan, J.F., Roche, B., 2015. Environmental transmission of Mycobacterium ulcerans drives dynamics of Buruli ulcer in endemic regions of Cameroon. Sci. Rep., 5, 18055. https://doi.org/10.1038/srep18055 García-Peña, G.E., Garchitorena, A., Carolan, K., Canard, E., Prieur-Richard, A.H., Suzán, G.A., Mills J.N., Roche, B., Guégan J.F., 2016. Niche-based host extinction increases prevalence of an environmentally acquired pathogen. Oikos 125, 1508-1515. https://doi.org/10.1111/oik.02700 Garin, J.P., Piens, M.A., Pratlong, F., Rioux, J.A., 1989. Leishmania braziliensis Vianna, 1911 en Guyane Française. Bull. Soc. Pathol. Exot., 82, 233-235.

Gay, N., Le Hello, S., Weill, F.X., de Thoisy, B., Berger, F., 2014. Salmonella serotypes in reptiles and humans, French Guiana. Vet. Microbio., 170, 167-171. https://doi.org/10.1016/j.vetmic.2014.01.024 Gharbi, M., Quénel, P., Gustave, J., Cassadou, S., La Ruche, G., Girdary, L., Marrama, M., 2011. Time series analysis of dengue incidence in Guadeloupe, French West Indies: forecasting models using climate variables as predictors. BMC Infect. Dis., 11, 166. https://doi.org/10.1186/1471-2334-11-166 Girod, R., Roux, E., Berger, F., Stefani, A., Gaborit, P., Carinci, R., Issaly, J., Carme, B., Dusfour, I., 2011. Unravelling the relationships between Anopheles darlingi (Diptera: Culicidae) densities, environmental factors and malaria incidence: understanding the variable patterns of malarial transmission in French Guiana (South America). Ann. Trop. Med. Parasitol., 105, 107-122.

http://doi.org/10.1179/136485911X12899838683322

Goldenfeld, N., Kadanoff, L.P., 1999. Simple lessons from complexity. Science 284, 87-89. https://doi.org/10.1126/science.284.5411.87 Gond, V., Freycon, V., Molino, J.F., Brunaux, O., Ingrassia, F., Joubert, P., Pekel, J.F., Prévost, M.F., Thierron, V., Trombe, P.J., Sabatier, D., 2011. Broad-scale spatial pattern of forest landscape types in the Guiana Shield. Int. J. Applied Earth Obs. Geoinfo., 13: 357-367.

https://doi.org/10.1016/j.jag.2011.01.004

Gottdenker, N.L., Chaves, L.F., Calzada, J.E., Saldana, A., Carroll, C.R., 2012. Host life history strategy, species diversity, and habitat influence Trypanosoma cruzi Vector infection in changing landscapes. PLoS Negl. Trop. Dis., 6, e1884. https://doi.org/10.1371/journal.pntd.0001884 Gourbière, S., Dorn, P., Tripet, F., Dumonteil, E., 2012. Genetics and evolution of triatomines: from phylogeny to vector control. Heredity 108, 190-202. https://doi.org/10.1038/hdy.2011.71 Guégan, J.-F., Ayouba, A., Cappelle, J., de Thoisy, 2020. Emerging infectious diseases and tropical forests: unleashing the beast within. Environn. Res. Lett., 15, 083007. 
Guidez, A., Pocquet, N., Restrepo, J., Mathieu, L., Gaborit, P., Issaly, J., Carinci, R., Chandre, F., Epelboin, Y., Romain, G., Dusfour, I. 2020. Spatio-temporal multiple insecticide resistance in Aedes aegypti populations in French Guiana: need for alternative vector control. Mem Inst. Oswaldo Cruz, 115. https://doi.org/10.1590/0074-02760200313

Guitet, S., Freycon, V., Brunaux, O., Pélissier, R., Sabatier, D., Couteron, P., 2016. Geomorphic control of rain-forest floristic composition in French Guiana: more than a soil filtering effect? J. Trop. Ecol., 32, 22-40. https://doi.org/10.1017/\$0266467415000620

Guitet, S., Cornu, J.F., Brunaux, O., Betbeder, J., Carozza, JM., Richard-Hansen, C., 2013. Landform and landscape mapping, French Guiana (South America). J. Maps 9, 325-335.

https://doi.org/10.1080/17445647.2013.785371

Hales, S., Weinstein, P., Woodward, A., 1996. Dengue fever epidemics in the South Pacific: driven by El Niño southern oscillation? Lancet 348, 1664-1665. https://doi.org/ 10.1016/S0140-6736(05)657376

Hammond, D.S., Gond, V., de Thoisy, B., Forget, P.M., DeDijn, B., 2007. Causes and consequences of a tropical forest gold rush in the Guiana Shield, South America. Ambio, 36, 661-670.

https://doi.org/10.1579/0044-7447(2007)36[661:CACOAT]2.0.CO;2

Han, B.A., Kramer, A.M., Drake, J.M., 2016. Global patterns of zoonotic disease in mammals. Trends Parasitol. 32, 565-577. https://doi.org/10.1016/j.pt.2016.04.007

Hanf, M., Adenis, A., Nacher, M., Carme, B., 2011. The role of El Niño southern oscillation (ENSO) on variations of monthly Plasmodium falciparum malaria cases at the cayenne general hospital, 19962009, French Guiana. Malaria J., 10, 100. https://doi.org/10.1186/1475-2875-10-100 Hansen, M.C., Potapov, P.V., Moore, R., Hancher, M., Turubanova, S.A., Tyukavina, A., Thau, D., Stehman, S.V., Goetz, S.J., Loveland, T.R., Kommareddy, A., Egorov, A., Justice, C.O., Townshend, J.G.R., 2013. High-resolution global maps of 21st-century forest cover change. Science, 342, 850-853. https://doi.org/10.1126/science.1244693

Hens, N., Aerts, M., Faes, C., Shkedy, Z., Lejeune, O., van Damme, P., Beutels, P., 2010. Seventy-five years of estimating the force of infection from current status data. Epidemiol. Infect., 138, 802-812. https://doi.org/10.1017/S0950268809990781

Hoen, B., Schaub, B., Funk, A.L., Ardillon, V., Boullard, M., Cabié, A., Callier, C., Carles, G., Cassadou, S., Césaire, R., Douine, M., Herrmann-Storck, C., Kadhel, P., Laouénan, C., Madec, Y., Monthieux, A., Nacher, M., Najioullah, F., Rousset, D., Ryan, C., Schepers, K., Stegmann-Planchard, S., Tressières, B., Voluménie, JL, Yassinguezo, S., Janky, E., Fontanet, A., 2018. Pregnancy Outcomes after ZIKV Infection in French Territories in the Americas. N. Engl. J. Med., 378, 985-994.

https://doi.org/10.1056/NEJMoa1709481 
Hosseini, P.R., Mills, J.N., Prieur-Richard, A.H., Ezenwa, V.O., Bailly, X., Rizzoli, A., Suzan, G.A., Vittecoq, M., García-Peña, G.E., Daszak, P., Guégan, J.F., Roche, B. 2017. Does the impact of biodiversity differ between emerging and endemic pathogens? The need to separate the concepts of hazard and risk. Phil. Trans. Royal Soc, London, Series B, 372: 20160129.

https://doi.org/10.1098/rstb.2016.0129

Hozé, N., Salje, H., Rousset, D, Fritzell, C., Vanhomwegen, J., Bailly, S., Najm, M., Enfissi, A., Manuguerra, J.C., Flamand, C., Cauchemez, S. 2020. Reconstructing Mayaro virus circulation in French Guiana shows frequent spillovers. Nature Comm. 11, 2842. https://doi.org/10.1038/s41467-020-16516-x Huang, C.I., Kay, S.C., Davis, S., Tufts, D.M., Gaffett., K., Tefft, B., Diuk-Wasser, M.A., 2019. High burdens of Ixodes scapularis larval ticks on white-tailed deer may limit Lyme disease risk in a low biodiversity setting. Ticks Tick-Borne Dis., 10, 258-268. https://doi.org/10.1016/j.ttbdis.2018.10.013 Huguin, M., Arechiga-Ceballos, N., Delaval, M., Guidez, A., Jorge de Castro, I., Lacoste, V., Salmier, A., Aguilar Setien, A., Silva, C.R., Lavergne, A., de Thoisy, B., 2018. How social structure drives the population dynamics of the common vampire bat (Desmodus rotundus, Phyllostomidae)? J Hered 109: 393-404. https://doi.org/10.1093/jhered/esx111

IPCC, 2019. IPCC Special report on climate change, desertification, land degradation, sustainable land management, food security, and greenhouse gas fluxes in terrestrial ecosystems.

https://www.ipcc.ch/site/assets/uploads/2019/08/Edited-SPM_Approved_Microsite_FINAL.pdf Ioos, S., Mallet, H.P., Leparc Goffart, I., Gauthier, V., Cardoso, T., Herida, M., 2014. Current Zika virus epidemiology and recent epidemics. Med. Mal. Infect., 44, 302-307.

https://doi.org/10.1016/j.medmal.2014.04.008 Jagadesh, S., Combe, M., Couppié, P., Le Turnier, P., Epelboin, L., Nacher, M., Gozlan, R.E., 2019. Emerging human infectious diseases of aquatic origin: a comparative biogeographic approach using Bayesian spatial modelling. Int. J. Health Geo, 18, 23. https://doi.org/10.1186/s12942-019-0188-6 Johansson, M.A., Cummings, D.A., Glass, G.E., 2009. Multiyear climate variability and dengue- El Niño southern oscillation, weather, and dengue incidence in Puerto Rico, Mexico, and Thailand: a longitudinal data analysis. PLoS Med., 6, e1000168. https://doi.org/10.1371/journal.pmed.1000168 Johnson, P.T.J., de Roode, J.J.C., Fenton, A., 2015. Why infectious disease research needs community ecology? Science 349, 1069-1075. https://doi.org/10.1098/rstb.2016.0129 Karl, S., Halder, N., Kelso, J.K., Ritchie, S.A., Milne, G.J., 2014. A spatial simulation model for dengue virus infection in urban areas. BMC Infect Dis. 14, 447. https://doi.org/10.1186/1471-2334-14-447 Kerr, L., Kendall, C., de Sousa, C. A. B., Frota, C. C., Graham, J., Rodrigues, L., Lima Fernandes M, Barreto, M.L., 2015. Human-armadillo interaction in Ceará, Brazil: Potential for transmission of Mycobacterium leprae. Acta Trop., 152, 74-79. https://doi.org/10.1016/j.actatropica.2015.07.023 
Kilpatrick, A.M., Salkeld, D.J., Titcomb, G,, Hahn, M.B., 2017. Conservation of biodiversity as a strategy for improving human health and well-being. Phil. Trans. Royal Soc. B, https://doi.org/10.1098/rstb.2015.0473.

Knapp, J., Chirica, M., Simonnet, C., Grenouillet, F., Bart, J.M., Sako, Y., Itoh, S., Nakao, M., Itoh, A., Millon, L., 2009. Echinococcus vogeli infection in a hunter, French Guiana. Emerg. Infect. Dis., 15, 2029-2031. https://doi.org/ 10.3201/eid1512.090940

Kocher, A., Gantier, J.C., Gaborit, P., Zinger, L., Holota, H., Valière, S., Dusfour, I., Girod, R., Bañuls, A.L., Murienne, J. 2017a. Vector soup: high-throughput identification of Neotropical phlebotomine sand flies using metabarcoding. Mol. Ecol. Resour., 17, 172-182. https://doi.org/10.1111/17550998.12556

Kocher, A., Valière, S., Bañuls, A.L., Murienne, J., 2017c. High-throughput sequencing of kDNA amplicons for the analysis of Leishmania minicircles and identification of Neotropical species. Parasitology, 145, 585-594. https://doi.org/10.1017/S0031182017002013

Kocher, A., de Thoisy, B., Catzeflis, F., Valière, S., Bañuls, AL., Murienne, J., 2017b. iDNA screening: disease vectors as vertebrate samplers. Mol., Ecol., 26, 6478-6486.

https://doi.org/10.1111/mec.14362

Kocher, A., de Thoisy, B., Catzeflis, F., Huguin, M., Valière, S., Zinger, L., Bañuls, A.L., Murienne, J., 2017d. Evaluation of short mitochondrial metabarcodes for the identification of Amazonian mammals. Meth. Ecol. Evol., 8, 1276-1283. https://doi.org/10.1111/2041-210X.12729

Lainson, R., Shaw, J.J., 2010. New world leishmaniasis, in: Topley \& Wilson's Microbiology and Microbial Infections. American Cancer Society. https://doi.org/10.1002/9780470688618.taw0182 Lavergne, A., de Thoisy, B., Donato, D., Guidez, A., Matheus, S., Catzeflis, F., Lacoste, V., 2015. Patawa Virus, a new Arenavirus hosted by forest rodents in French Guiana. EcoHealth, 12, 339-346. https://doi.org/10.1007/s10393-014-0971-6 Lavergne, A., de Thoisy, B., Tirera, S., Donato, D., Bouchier, C., Lacoste, V., 2016. Identification of lymphocytic choriomeningitis mammarenavirus in house mouse (Mus musculus, Rodentia) in French Guiana. Infection, Genetics, Evol. 37, 225-230. https://doi.org/10.1016/j.meegid.2015.11.023 Le Turnier, P., Mosnier, E., Schaub, R., Bourhy, P., Jolivet, A., Cropet, C., Villemant, N., TrombertPaolantoni, S., Berlioz-Arthaud, A., Nacher, M., Demar, M., Picardeau, M., Djossou, F., Epelboin, L., 2018. Epidemiology of Human Leptospirosis in French Guiana (2007-2014): a retrospective study. Am. J. Trop. Med. Hyg., 99, 590-596. https://doi.org/10.4269/ajtmh.17-0734.

Li, Z., Roux, E., Dessay, N., Girod, R., Stéfani, A., Nacher, M., Moiret, A., Seyler, F., 2016. Mapping a knowledge-based Malaria hazard index related to landscape using remote sensing: application to the cross-border area between French Guiana and Brazil. Remote Sens., 8, 319.

https://doi.org/10.3390/rs8040319 
Li, Z., Catry, T., Dessay, N., Roux, E., Mahe, E., Seyler, F., 2016. Multi-sensor data fusion for identifying malaria environmental features. In: International Geoscience and Remote Sensing Symposium (IGARSS). 2016. https://doi.org/10.1109/IGARSS.2016.7729653

Loiseau, R., Nabet, C., Simon, S., Ginouves, M., Brousse, P., Blanchet, D., Demar, M., Couppié, P., Blaizot, R., 2019. American cutaneous leishmaniasis in French Guiana: an epidemiological update and study of environmental risk factors. Int. J. Dermatol., 58, 1323-1328.

https://doi.org/10.1111/ijd.14625

Lopez-Osorio, F., Miranda-Esquivel, D.R., 2010. A phylogenetic approach to conserving Amazonian biodiversity. Cons. Biol., 24, 1359-1366. https://doi.org/10.1111/j.1523-1739.2010.01482.x

Luis, A.D., Kuenzi, A.J., Mills, J.N., 2018. Species diversity concurrently dilutes and amplifies transmission in a zoonotic host-pathogen system through competing mechanisms. PNAS, 115, 7979-7984.

https://doi.org/10.1073/pnas.1807106115

Macdonald, G. 1956. Epidemiological basis of malaria control. Bull World Health Organ. 15, 613-626. Marie-Joseph, I., Linguet, L., Gobinddass, M.L., Wald, L., 2013. On the applicability of the Heliosat-2 method to assess surface solar irradiance in the Intertropical Convergence Zone, French Guiana. Int. J. Remote Sens., 34, 3012-3027. https://doi.org/10.1080/01431161.2012.756598

Matheus, S., Lavergne, A., de Thoisy, B., Dussart, P., Lacoste, V. 2012. Complete genome sequence of a novel Hantavirus variant of Rio Mamoré virus, Maripa virus, from French Guiana. J. Virol., 86, 5399. https://doi.org/10.1128/JVI.00337-12

Matheus, S., Kallel, H., Mayence, C., Bremand, L., Houcke, S., Rousset, D., Lacoste, V., de Thoisy, B., Hommel, D., Lavergne, A., 2017. Hantavirus pulmonary syndrome by Maripa virus in French Guiana, 2008-2016. Emerg. Infect. Dis., 23, 1722-1725. https://doi.org/10.3201/eid2310.170842

Medkour, H., Davoust, B., Dulieu, F., Maurizi, L., Lamour, T., Marié, J.L., Mediannikov, O., 2019a. Potential animal reservoirs (dogs and bats) of human visceral leishmaniasis due to Leishmania infantum in French Guiana. PLoS Negl Trop Dis., 13, e0007456. https://doi.org/10.1371/journal.pntd.0007456 Medkour, H., Davoust, B., Levasseur, A., Mediannikov, O., 2019b. Molecular Evidence of Leishmania infantum and Leishmania guyanensis in red howler monkey (Alouatta seniculus) from French Guiana. Vector Borne Zoonotic Dis., 19, 896-900. https://doi.org/10.1089/vbz.2019.2459

Melenotte. C., Caputo, A., Bechah, Y., Lepidi, H., Terras, J., Kowalczewska, M., Di Pinto, F., Nappez, C., Raoult, D., Bregeon, F. 2019. The hypervirulent Coxiella burnetii Guiana strain compared in silico, in vitro and in vivo to the Nine Mile and the German strain. Clin Microbiol Infect., 25, 1155-e1. https://doi.org/10.1016/j.cmi.2018.12.039

Messina, J.P., Kraemer, M.U., Brady, O.J., Pigott, DM, Shearer, F.M., Weiss, D.J., Golding, N., Ruktanonchai, C.W., Gething P.W., Cohn, E., Brownstein, J.S., Khan, K., Tatem, A.J., Jaenisch, T., Mur- 
ray, C.J.L., Marinho, F., Scott, T.W., Hay, S.I., 2016). Mapping global environmental suitability for Zika virus. Elife 5, e15272. Htpps://doi.org/ 10.7554/eLife.15272

Morris A., Gozlan R.E., Hassani H., Andreou D., Couppié P. and Guégan J.F., 2014. Complex temporal climate signals drive the emergence of human water-borne disease. Emerg. Microbes and Infections, 3, e56. https://doi.org/10.1038/emi.2014.56

Morris, A., Gozlan, R.E., Marion, E., Marsollier, L., Andreou, D., Sanhueza, D., Ruffine, R., Couppié, P., Guégan, J.-F., 2014b. First detection of Mycobacterium ulcerans DNA in environmental samples from South America. PLoS Negl. Trop. Dis., 30, e2660. doi: 10.1371/journal.pntd.0002660

Morris, A., Guégan J.-F., Andreou, D., Marsollier, L., Carolan, K., Le Croller, M., Sanhueza, D., Gozlan, R.E., 2016. Deforestation-driven food web collapse linked to emerging tropical disease, Mycobacterium ulcerans. Sci. Adv., 2, e1600387. https://doi.org/ 10.1126/sciadv.1600387

Morris, A., Guégan, J.-F., Benbow, M.E., Williamson, H., Small, P.L.C., Quaye, C., Boakye, D., Merritt, R.W., Gozlan R.E., 2016b. Functional diversity as a new framework for understanding the ecology of an emerging generalist pathogen. EcoHealth, 13, 570-581. https://doi.org/10.1007/s10393-016$1140-x$

Mosnier, E., Roux, E., Cropet, C., Lazrek, Y., Moriceau, O, Gaillet, M., Mathieu, L., Nacher, M., Demar, M., Odonne, G., Douine, M., Michaud, C., Pelleau, S., Djossou, F., Musset, L., 2020. Prevalence of Plasmodium spp. In the Amazonian border context (French Guiana-Brazil) : associated factors and spatial distribution. Am. J. Trop. Med. Hyg., 102, 130-141. https://doi.org/10.4269/ajtmh.19-0378 Mosnier, E., Dusfour, I., Lacour, G., Saldanha, R., Guidez, A., Gomes, M.S., Sanna, A., Epelboin, Y., Restrepo, J., Davy, D., Demar, M., Djossou, F., Douine, M., Ardillon, V., Nacher, M., Musset, L., Roux, E., 2020. Resurgence risk for malaria, and the characterization of a recent outbreak in an Amazonian border area between French Guiana and Brazil. BMC Infect Dis., 20, 373.

https://doi.org/10.1186/s12879-020-05086-4

Moua, Y., Roux, E., Dusfour, I., de Thoisy, B., Seyler, F., Briolant, S., 2017. Distribution of the habitat suitability of the main malaria vector in French Guiana using Maximum Entropy Modeling. J. Med. Entomol., 54, 606-621. https://doi.org/10.1093/jme/tjw199

Murray, K.A., Olivero, J., Roche, B., Tiedt, S., Guégan, J.F., 2018. Pathogeography: leveraging the biogeography of human infectious diseases for global health management. Ecography 41, 1411-1427. https://doi.org/10.111/ecog.03625

Musset, L., Pelleau, S., Girod, R., Ardillon, V., Carvalho, L., Dusfour, I., Gomes, M.S., Djossou, F., Legrand, E., 2014. Malaria on the Guiana Shield: a review of the situation in French Guiana. Mem Inst Oswaldo Cruz 109, 525-533. https://doi.org/10.1590/0074-0276140031

Musso, D., 2015. Zika Virus Transmission from French Polynesia to Brazil. Emerg. Infect. Dis., 21, 1887. http://dx.doi.org/10.3201/eid2110.151125 
Nacher, M., 2020. Santé globale et Guyane : étude descriptive et comparative de quelques grands indicateurs. Bull. Epidémio. Hebdo., 2-3. http://beh.santepubliquefrance.fr/beh/2020/2-3/2020_23_1.html

Orjuela, L.I., Morales, J.A., Ahumada, M.L., Rios, J.F., González, J.J., Yañez, J., Rosales, A., Cabarcas, D.M., Venegas, J., Yasnot, M.F., Quiñones, M.L., 2018. Insecticide resistance and its intensity in populations of Malaria vectors in Colombia. Biomed. Res. Int., 2018, 9163543.

https://doi.org/10.1155/2018/9163543

Orjuela, L.I., Álvarez-Diaz, D.A., Morales, J.A., Grisales, N., Ahumada, M.L., Venegas, H.J., Quiñones, M.L., Yasnot, M.F., 2019. Absence of knockdown mutations in pyrethroid and DDT resistant populations of the main malaria vectors in Colombia. Malar J., 18, 384. https://doi.org/10.1186/s12936019-3034-1

Ostfeld, R.S., Keesing, F., 2000. Biodiversity and disease risk: the case of Lyme disease. Cons. Biol., 14, 722-728. https://doi.org/10.1046/j.1523-1739.2000.99014.x

Park, A.W., Cleveland, C.A., Dallas, T.A., Corn, J.L., 2016. Vector species richness increases haemorrhagic disease prevalence through functional diversity modulating the duration of seasonal transmission. Parasitol., 143, 874-879. https://doi.org/10.1017/S0031182015000578

Parselia, E., Kontoes, C., Tsouni, A., Christodoulou, C., Kioutsioukis, I., Magiokinis, G., Sttilianakis, N., 2019. Satellite earth observation data in epidemiological modeling of Malaria, Dengue and West Nile Virus: a scoping review. Remote Sens., 11: 1862. https://doi;org/10.3390/rs11161862

Peneau, J., Nguyen, A., Flores-Ferrer, A., Blanchet, D., Gourbière, S., 2016. Amazonian Triatomine biodiversity and the transmission of Chagas disease in French Guiana: in medio stat sanitas. PLoS Negl Trop Dis., 10: e0004427. https://doi.org/10.1371/journal.pntd.0004427 Pelleau, S., Moss, E.L., Dhingra, S.K., Volney, B., Casteras, J., Gabryszewski, S.J., Volkman, S.K., Wirth, D.F., Legrand, E., Fidock, D.A., Neafsey, D.E., Musset, L., 2015. Adaptive evolution of malaria parasites in French Guiana: Reversal of chloroquine resistance by acquisition of a mutation in pfcrt. Proc Natl Acad Sci., 112, 11672-11677. https://doi.org/10.1073/pnas.1507142112

Petersen, L.R., Jamieson, D.J., Honein, M.A., 2016. Zika Virus. N. Engl. J. Med., 375, 294-295. https://doi.org/ 10.1056/NEJMra1602113

Petrakovsky, J., Bianchi, A., Fisun, H., Nájera-Aguilar, P., Pereira, M.M., 2014. Animal leptospirosis in Latin America and the Caribbean countries: reported outbreaks and literature review (2002-2014). Int. J. Environ. Res. Public Health, 11, 10770-10789. https://doi.org/10.3390/ijerph111010770 Phan, T. G., del Valle Mendoza, J., Sadeghi, M., Altan, E., Deng, X., \& Delwart, E. 2017. Sera of Peruvians with fever of unknown origins include viral nucleic acids from non-vertebrate hosts. Virus Genes, 54, 33-40. https://doi.org/10.1007/s11262-017-1514-3

Pialoux, G., Gaüzère, B.A., Jauréguiberry, S., Strobel, M., 2007. Chikungunya, an epidemic arbovirosis. 
Lancet Infect. Dis., 7, 319-327. https://doi.org/10.1016/S1473-3099(07)70107-X

Picardeau, M., 2013. Diagnosis and epidemiology of leptospirosis. Med Mal Infect., 43, 1-9.

https://doi.org/10.1016/j.medmal.2012.11.005

Pigott, D.M., Bhatt, S., Golding, N., Duda, K.A., Battle, K.E., Brady, O.J., Messina, J.P., Balard, Y., Bastien, P., Pratlong, F., Brownstein, J.S., Freifeld, C.C., Mekaru, S.R., Gething, P.W., George, D.B., Myers, M.F., Reithinger, R., Hay, S.I., 2014. Global distribution maps of the leishmaniases. Elife, 3, e02851. Htpps://doi.org/ 10.7554/eLife.02851

Pommier de Santi, V., Dia, A., Adde A., Hyvert G., Galant J., Mazevet M., Nguyen C., Vezenegho S.B., Dusfour I., Girod R., Briolant S., 2016a. Malaria in French Guiana linked to illegal gold mining. Emerg. Infect. Dis., 22, 344-346. https://doi.org/ 10.3201/eid2202.151292

Pommier de Santi, V., Djossou, F., Barthes, N., Bogreau, H., Hyvert, G., Nguyen, C., Pelleau, S., Legrand, E., Musset, L., Nacher, M., Briolant, S. 2016b. Malaria hyperendemicity and risk for Artemisinin resistance among illegal gold miners, French Guiana. Emerg. Infect. Dis., 22, 903-906.

https://doi.org/ 10.3201/eid2205.151957

Pommier de Santi, V., Girod, R., Mura, M., Dia, A., Briolant, S., Djossou, F., Dusfour, I., Mendibil, A., Simon, F., Deparis, X., Pagès, F., 2016. Epidemiological and entomological studies of a malaria outbreak among French armed forces deployed at illegal gold mining sites reveal new aspects of the disease's transmission in French Guiana. Malar. J., 2, 15:35. https://doi.org/10.1186/s12936-0161088-x

Pommier de Santi, V., Marié, J.L., Briolant, S,. Mahamat A., Djossou F., Epelboin, L., Lamour, T., De Thoisy, B., Raoult, D., Edouard, S., Davoust, B., 2016. Spécificités épidémiologiques de la fièvre Q en Guyane. Bull. Acad. Vét. France, 169, 148-54. https://doi.org/10.4267/2042/61397 Pommier de Santi, V., Dusfour, I., de Parseval, E., Lespinet, B., Nguyen, C., Gaborit, P., Carinci, R., Hyvert, G., Girod, R., Briolant, S. 2017. Risk of daytime transmission of malaria in the French Guiana rain forest. Med. Santé Trop., 27, 111-112. https://doi.org/ 10.1684/mst.2017.0659

Poveda, G., Rojas, W., Quinones, M.L., Velez, I.D., Mantilla, R.I., Ruiz, D., Zuluaga, J.S., Rua, G.L., 2001. Coupling between annual and ENSO timescales in the malaria-climate association in Colombia. Environ. Health Perspect., 109, 489-493. https://doi.org/10.1289/ehp.01109489

Powers, A.M., Logue, C.H., 2007. Changing patterns of chikungunya virus: re-emergence of a zoonotic arbovirus. J. Gen. Virol., 88, 2363-2377. https://doi.org/10.1099/vir.0.82858-0

Prost, M.T., Lointier M. 1987. Sedimentology and stratigraphy of the Holocene formations of the French Guiana coastal plain. IGCP Project 201 Mérida, meeting, 55-83 Rabinovich, J., Feliciangeli, M.D. 2004. Parameters of Leishmania braziliensis transmission by indoor Lutzomyia ovallesi in Venezuela. Am. J. Trop. Med. Hyg ., 70, 373-382.

https://doi.org/10.4269/ajtmh.2004.70.373 
Randolph, S.E., Dobson, A.D.M. 2012. Pangloss revisited: a critique of the dilution effect and the biodiversity-buffers-disease paradigm. Parasitology 139, 847-863.

https://doi.org/10.1017/S0031182012000200

Robinson, M.C. 1955. An epidemic of virus disease in Southern Province, Tanganyika Territory, in 1952-53. I. Clinical features. Trans. R. Soc. Trop. Med. Hyg., 49, 28-32.

Roche, B., Dobson, A.P., Guégan, J.F., Rohani, P., 2012. Linking community and disease ecology: the impact of biodiversity on pathogen transmission. Phil. Trans. Royal Soc. London, ser. B, 367: 28072813. https://doi.org/10.1098/rstb.2011.0364

Roche, B., Rohani, P., Dobson, A.P., Guégan, J.F., 2013. The Impact of community organization on vector-borne pathogens. Am. Nat., 181, 1-11. https://doi.org/10.1086/668591

Roger, A., Nacher, M., Hanf, M., Drogoul, A.S., Adenis, A., Basurko, C., Dufour, J., Sainte Marie, D., Blanchet, D., Simon, S., Carme, B., Couppie, P. 2013. Climate and Leishmaniasis in French Guiana. Am. J. Trop. Med. Hyg., 89, 564-569. https://doi.org/10.4269/ajtmh.12-0771

Roger, F., Godhe, A., Gamfeldt, L. 2012. Genetic diversity and ecosystem functioning in the face of multiple stressors. PLoS One, 7, e45007. https://doi.org/10.1371/journal.pone.0045007

Rotureau, B., 2006. Ecology of the Leishmania species in the Guianan ecoregion complex. Am. J. Trop. Med. Hyg., 74, 81-96. https://doi.org/10.4269/ajtmh.2006.74.81

Rougeron, V., Sam, I.C., Caron, M., Nkoghe, D., Leroy, E., Roques P. 2015. Chikungunya, a paradigm of neglected tropical disease that emerged to be a new health global risk. J. Clin. Virol., 64, 144-152. https://doi.org/10.1016/j.jcv.2014.08.032

Roux, E., Venâncio, A.F., Girres J.F., Romaña C.A. 2011. Spatial patterns and eco-epidemiological systems - part II: characterising spatial patterns of the occurrence of the insect vectors of Chagas disease based on remote sensing and field data. Geospat. Health, 6, 53-64. https://doi.org/ 10.4081/gh.2011.157

Roux, E., Gaborit, P., Romaña, C.A., Girod, R., Dessay, N., Dusfour, I., 2013. Objective sampling design in a highly heterogeneous landscape - characterizing environmental determinants of malaria vector distribution in French Guiana, in the Amazonian region. BMC Ecol., 13, 45.

https://doi.org/10.1186/1472-6785-13-45

Saldanha, R., Mosnier, E., Barcellos, C., Carbunar, A., Charron, C., Desconnets, J.C., Guarmit B., Gomes M.D.S.M., Mandon, T., Mendes, A.M., Peiter, P.C., Musset, L., Sanna, A., Van Gastel, B., Roux, E., 2020. Contributing to elimination of cross-border Malaria through a standardized solution for case surveillance, data sharing, and data interpretation: development of a cross-border monitoring system. JMIR Public Health Surveill 6, e15409. https://doi.org/10.2196/15409

Salgueiro, P., Restrepo-Zabaleta, J., Costa, M., Gallardo, A., Pinto, J., Gaborit, P., Guidez, A., Martins, A.J., Dusfour, I., 2019. Liaisons dangereuses: cross-border gene flow and dispersal of insecticide re- 
sistance-associated genes in the mosquito Aedes aegypti from Brazil and French Guiana. Mem Inst Oswaldo Cruz 114. https://doi.org/10.1590/0074-02760190120

Salje H, Cauchemez, S, Alera, MT, Rodriguez-Barraquer, I, Thaisomboonsuk, B, Srikiatkhachorn, A, Lago, CB, Villa, D, Klungthong, C., Tac-An, I.A., Fernandez, S., Velasco, J.M., Roque, V.G., Nisalak, A., Macareo, L.R., Levy, J.W., Cummings, D., Yoon, I.K., 2016. Reconstruction of 60 years of Chikungunya epidemiology in the Philippines demonstrates episodic and focal transmission. J. Infect. Dis., 213, 604-610. https://doi.org/10.1093/infdis/jiv470

Salkeld, D.J., Padgett, K.A., Jones, J.H., 2013. A meta-analysis suggesting that the relationship between biodiversity and risk of zoonotic pathogen transmission is idiosyncratic. Ecol Lett., 16, 679-686. https://doi.org/10.1111/ele.12101

Salmier, A., Tirera, S., de Thoisy, B., Franc, A., Darcissac, E., Donato, D., Bouchier, C., Lacoste, V., Lavergne, A., 2017. Virome analysis of two sympatric bat species (Desmodus rotundus and Molossus molossus) in French Guiana. PloS One 12, e0186943. https://doi.org/10.1371/journal.pone.0186943 Salomon, O., Wilson, M.L., Munstermann, L.E., Travi, B.L., 2004. Spatial and temporal patterns of phlebotomine sand flies (Diptera: Psychodidae) in a cutaneous leishmaniasis focus in northern Argentina. J Med Entomol., 41, 33-39. https://doi.org/10.1603/0022-2585-41.1.33

Sanchez, J.D., 2017. PAHO WHO | Regional Zika Epidemiological Update (Americas) January 26, 2017. Pan American Health Organization / World Health Organization.

Sanna, A., Andrieu, A., Carvalho, L., Mayence, C., Tabard, P., Hachouf, M. et al. (2018). Yellow fever cases in French Guiana, evidence of an active circulation in the Guiana Shield, 2017 and 2018. Eurosurveillance 23, pii=1800471. https://doi.org/10.2807/1560-7917.ES.2018.23.36.1800471

Santé Publique France, 2015. Surveillance du chikungunya. Le Point Epidémiologique. Available from: https://www.santepubliquefrance.fr/regions/guyane/documents/bulletin-regional/2015/situationepidemiologique-du-chikungunya-en-guyane.-point-au-27-novembre-2015 Santé Publique France, 2016. Situation épidémiologique du virus Zika aux Antilles Guyane. Available from: http://invs.santepubliquefrance.fr/Publications-et-outils/Points-epidemiologiques/Tous-lesnumeros/Antilles-Guyane/2016/Situation-epidemiologique-du-virus-Zika-aux-Antilles-Guyane.-Pointau-10-novembre-2016

Santé Publique France, 2020. Situation épidémiologique de la dengue en Guyane. Available from: https://www.santepubliquefrance.fr/regions/guyane/documents/bulletin-regional/2020/situationepidemiologique-de-la-dengue-en-guyane.-point-au-16-avril-2020

Sarkis, S., Dabo, S., Lise, M.C., Neuveut., C, Meurs, E.F., Lacoste, V., Lavergne, A., 2018. A potential robust antiviral defense state in the common vampire bat: Expression, induction and molecular characterization of the three interferon-stimulated genes-OAS1, ADAR1 and PKR. Develop Comp Immunol., 85, 95-107. https://doi.org/10.1016/j.dci.2018.04.006 
Schaub, R., Avanzi, C., Singh, P., Paniz-Mondolfi, A., Cardona-Castro, N., Legua, A., Crespo, L., Sewpersad, K., Dávila, J.J., Barreto, J., Dwivedi, P., Morris-Wilson, H., Paredes Larrea, M., Talhari, C., Lahiri, R., Truman, R.W., Gozlan, R.E., Couppié, P., de Thoisy, B. (2020. Leprosy transmission in Amazonian countries: current status and future trends. Current Tropical Medicine Reports. https://doi.org/10.1007/s40475-020-00206-1

Schmidt, K.A., Ostfeld, R.S., 2001. Biodiversity and the dilution effect in disease ecology. Ecology, 82, 609-619. https://doi.org/10.1890/0012-9658(2001)082[0609:BATDEI]2.0.CO;2

Simon, S., Nacher, M., Carme, B., Basurko, C., Roger, A., Adenis, A., Ginouves, M., Demar, M., Couppie, P., 2017. Cutaneous leishmaniasis in French Guiana: revising epidemiology with PCR-RFLP. Trop. Med. health, 45, 5. https://doi.org/10.1186/s41182-017-0045-x

Simon, S., de Thoisy, B., Mercier, A., Nacher, M., Demar, M. 2019. Virulence of atypical Toxoplasma gondii strains isolated in French Guiana in a murine model. Parasite, 26, 60. https://doi.org/ 10.1051/parasite/2019048

Soberon J, Peterson AT. 2005. Interpretation of models of fundamental Ecological Niches and Species' distributional areas. Biodivers. Informatics. https://doi.org/10.17161/bi.v2i0.4 Stanaway, J.D., Shepard, D.S., Undurraga, E.A., Halasa, Y.A., Coffeng, L.E., Brady, O.J., Hay, S.I., Bedi, N., Bensenor, I.M., Castañeda-Orjueal, C.A., Chuang, T.W., Gibney, K.B., Memish, Z.A., Rafay, A., Ukwaja, K., Yonemoto N., Murray; C.J.L., 2016. The Global burden of Dengue: an analysis from the Global Burden of Disease Study 2013. Lancet Infect. Dis. 16: 712-723. https://doi.org/10.1016/S14733099(16)00026-8

Stefani, A., Roux, E., Fotsing, J.M., Carme, B., 2011. Studying relationships between environment and malaria incidence in Camopi (French Guiana) through the objective selection of buffer-based landscape characterisations. Int. J. Health Geogr., 10, 65. https://doi.org/10.1186/1476-072X-10-65 Stier, A., de Carvalho, W.D., Rostain, S., Catzeflis, F., Claessens, O., Dewynter, M., McKey, D., Mustin, K., Palisse, M., de Thoisy, B. 2020. The Amazonian savannas of French Guiana: cultural and social importance, biodiversity, and conservation challenges. Trop. Conserv. Science 13, 1-21.

https://doi.org/10.1177/1940082919900471

Talaga, S., Leroy, C., Guidez, A., Dusfour, I., Girod, R., Dejean, A., \& Murienne, J., 2017. DNA reference libraries of French Guianese mosquitoes for barcoding and metabarcoding. PLoS One, 12, e0176993. https://doi.org/10.1371/journal.pone.0176993

Tirera, S., de Thoisy, B., Donato, D., Bouchier, C., Frigero, J.M., Lacoste, V., Franc A., Lavergne A. in prep. Habitat influence on viral diversity hosted by Neotropical rodents. Viruses.

Thill, P., Beillard, E., Bisser, S., Berlioz-Arthaud, A., Nacher, M., Djossou, F., Epelboin, L., 2019. High endemicity of $Q$ fever in French Guiana, Latin America: a cross-sectional study 2009-2017. 29th European Congress of Clinical Microbiology and Infectious Diseases, Amsterdam, Netherlands 
Tsetsarkin, K.A., Chen, R., Sherman, M.B., Weaver, S.C., 2011. Chikungunya virus: evolution and genetic determinants of emergence. Curr., Opin., Virol., 1, 310-317.

https://doi.org/10.1016/j.coviro.2011.07.004

UICN France, MNHN, GEPOG, Kwata, Biotope, Hydréco, OSL, 2017. La Liste rouge des espèces menacées en France - Chapitre de la Faune vertébrée de Guyane. Paris, France.

Ushio, M., Hsieh, C.H., Masuda, R., Deyle, E.R., Ye, H., Chang, C.W., Sugihara, G., Kondoh M., 2018. Fluctuating interaction network and time-varying stability of a natural fish community. Nature, 15, 360-363. https://doi.org/10.1038/nature25504

Vasconcelos-dos-Santos, T., Chaves, R.C.G., Prévot, G., Silveira, F.T., Póvoa, M.M., Rangel, E.F., 2019. Binational burden of American cutaneous leishmaniasis in Oiapoque, Amapá State, Brazil, bordering French Guiana. Rev. Soc. Bras. Med. Trop., 52. https://doi.org/10.1590/0037-8682-0256-2018.

Vezenegho, S.B., Adde, A., Pommier de Santi, V., Issaly, J., Carinci, R., Gaborit, P., Dusfour, I., Girod, R., Briolant, S. 2016. High malaria transmission in a forested malaria focus in French Guiana: How can exophagic Anopheles darlingi thwart vector control and prevention measures? Mem. Inst. Oswaldo Cruz 111, 561-9. http://dx.doi.org/10.1590/0074-02760160150

Vezenegho, S.B., Carinci, R., Issaly, J., Nguyen, C., Gaborit, P., Ferraro, L., Lacour, G., Mosnier, E., Pommier de Santi, V., Epelboin, Y., Girod, R., Briolant, S., Dusfour, I., 2020. Variation in pyrethroid resistance phenotypes in Anopheles darlingi from residual malaria transmission area: warning on suspected resistance built-up in French Guiana. bioRxiv. https://doi.org/10.1101/2020.12.21.423491 Volney, B., Pouliquen, J.F., de Thoisy, B., Fandeur, T., 2002. A seroepidemiological study of malaria in human and monkey populations in French Guiana. Acta Trop., 82, 11-23.

https://doi.org/10.1016/S0001-706X(02)00036-0

Wangdi, K., Gatton, M.L., Kelly, G.C., Clements, A.C.A. 2015. Cross-border malaria: a major obstacle for malaria elimination. Adv. Parasitol., 89, 79-107. https://doi.org/10.1016/bs.apar.2015.04.002 White, L.A., Forester, J.D., Craft, M.E., 2018. Dynamic, spatial models of parasite transmission in wildlife: their structure, applications and remaining challenges. J. Anim. Ecol., 87, 559-580.

https://doi.org/10.1111/1365-2656.12761

WHO, 2016. Leishmaniasis in high-burden countries: an epidemiological update based on data reported in 2014. Wkly Epidemiol Rec., 22, 285-296.

WHO, 2020. Chagas disease (American trypanosomiasis). https://www.who.int/news-room/factsheets/detail/chagas-disease-(american-trypanosomiasis).

Wu, X., Lu Y., Zhou, S., Chen, L., Xu, B., 2016. Impact of climate change on human infectious diseases: Empirical evidence and human adaptation. Env. Int. 86, 14-23.

https://doi.org/10.1016/j.envint.2015.09.007 
Wood, C.L., Lafferty, K.D., DeLeo, G., Young, H.S., Hudson, P.J., Kuris, A.M., 2014. Does biodiversity protect humans against infectious disease? Ecology, 95, 817-832. https://doi.org/10.1890/13-1041.1 Woolhouse, M. E., Gowtage-Sequeria, S., 2005. Host range and emerging and reemerging pathogens. Emerg. Infect. Dis., 11, 1842-1847. https://doi.org/ 10.3201/eid1112.050997

WorldBank, 2020. https://data.worldbank.org/indicator/SP.POP.GROW. Yozwiak, N.L., Skewes-Cox, P., Stenglein, M.D., Balmaseda, A., Harris, E., DeRisi J.L., 2012. Virus identification in unknown tropical febrile illness cases using deep dequencing. PLoS Negl Trop Dis., 6, e1485. https//:doi.org/10.1371/journal.pntd.0001485

Figure 1. Spatial distribution and temporal fluctuations of the Force of Infection by Trypanosoma cruzi in French Guiana. (A) Variations in the Force of Infection across the four types of French Guianese landscapes and their corresponding level of triatomine biodiversity. (B) Fluctuations in the force of infection by T. cruzi throughout the year. NC: the Northern Chain; CP: the Coastal Plain; IC: the Inini-Camopi Chain; CM: the Central Massif. The different colors in the histogram bars correspond to the different triatomine species found in French Guiana. From Péneau et al. (2016).

Figure 2. The Biotic-Abiotic-Movement (BAM) framework from the Eltonian ecological niche model and Elton's noise hypothesis. As the spatial scale increases, the importance of biotic parameters, e.g., host-parasite-human interactions, tends to vanish and abiotic parameters, e.g., climatic conditions, then become preponderant in explaining observed distribution patterns. In contrast, when scaling down, biotic explanations gain importance to the detriment of abiotic parameters (for simplicity, in the BAM diagram comparison $\mathrm{M}$ has been kept constant but it can change depending on the spatial scale as well). For cutaneous leishmaniasis, climatic factors better explain the spatial distribution of human cases at the South American continent scale, whereas wildlife-ecosystems-human activities better explain their distribution at the French Guiana territory spatial scale. Therefore, depending on the scale at which the research was done, different explanations may appear to explain disease patterns. Adapted from Chavy et al. (2019a). 
Table 1. Main research and biomedical facilities for the development of long-term environmental and epidemiological surveillance of old and recent human infectious diseases in French Guiana.

\begin{tabular}{|c|c|c|}
\hline Main context characteristics and facilities & $\begin{array}{l}\text { Implications and advantages for re- } \\
\text { search and biomedicine }\end{array}$ & Some references \\
\hline $\begin{array}{l}\text { Concentration of research and biomedical } \\
\text { activities and institutes on a small area (i.e., } \\
\sim 15,000 \mathrm{~km}^{2} \text { ) }\end{array}$ & $\begin{array}{l}\text { Current research context facilitates and } \\
\text { promotes transdisciplinarity, integrative } \\
\text { studies and synthesis }\end{array}$ & Guégan et al. 2020 \\
\hline $\begin{array}{l}\text { High speed (logistic facilities) between } \\
\text { sampling and data storage / processing in } \\
\text { the laboratory }\end{array}$ & $\begin{array}{l}\text { Reduced loss of materials and samples } \\
\text { in harsh tropical environmental condi- } \\
\text { tions }\end{array}$ & $\begin{array}{l}\text { Chavy et al. 2019b; } \\
\text { Kocher et al. } 2017 b ; \\
\text { Brioland et al. } 2020\end{array}$ \\
\hline $\begin{array}{l}\text { Knowledge of biodiversity and ongoing } \\
\text { programs (ecology, taxonomy, conserva- } \\
\text { tion) compared to other regions in the } \\
\text { world }\end{array}$ & $\begin{array}{l}\text { Even if there is significant biodiscovery } \\
\text { work, research can go faster and deep- } \\
\text { er on distinct disease systems }\end{array}$ & $\begin{array}{l}\text { Morris et al. } 2014 b ; \\
\text { Peneau et al. } 2016 ; \\
\text { de Thoisy et al. } 2014\end{array}$ \\
\hline $\begin{array}{l}\text { Knowledge of socioeconomic, anthropo- } \\
\text { logical, } \\
\text { epidemiological conditions of local com- } \\
\text { munities }\end{array}$ & $\begin{array}{l}\text { Can better measure the respective } \\
\text { weight of the different drivers in mor- } \\
\text { bidity and mortality cases }\end{array}$ & $\begin{array}{l}\text { Matheus et al. 2017; } \\
\text { Mosnier et al. 2020; } \\
\text { Nacher } 2020\end{array}$ \\
\hline $\begin{array}{l}\text { Several research stations and biomedical } \\
\text { monitoring, } \\
\text { including for indigenous populations, } \\
\text { dense network of } \\
\text { spatial surveillance and large research and } \\
\text { biomedical } \\
\text { community of researchers and medical } \\
\text { doctors }\end{array}$ & $\begin{array}{l}\text { Research context favorizes long-term } \\
\text { observations and the analysis of many } \\
\text { disease systems and their dynamics } \\
\text { with respect to spatiotemporal variation } \\
\text { of their main determinants. Massive } \\
\text { sequencing (e.g., virome, bacteriome, } \\
\text { and high-throughput serological stud- } \\
\text { ies in situ }\end{array}$ & $\begin{array}{l}\text { Musset et al. 2014; } \\
\text { Le Turnier et al. } \\
\text { 2018; Chavy et al. } \\
\text { 2019a; Hozé et al. } \\
\text { 2020; Salmier et al. } \\
\text { 2017; Adde et al. } \\
\text { 2016a }\end{array}$ \\
\hline Space station and space observation & $\begin{array}{l}\text { Real-time data acquisition on environ- } \\
\text { mental changes }\end{array}$ & $\begin{array}{l}\text { Roux et al. 2012, } \\
2013\end{array}$ \\
\hline $\begin{array}{l}\text { Substantial and long-term biomedical } \\
\text { literacy in tropical medicine and hygiene as } \\
\text { well as ecology/biodiversity }\end{array}$ & $\begin{array}{l}\text { Research context promotes transdisci- } \\
\text { plinarity and curiosity as well as strong } \\
\text { interactions with the biomedical com- } \\
\text { munity }\end{array}$ & $\begin{array}{l}\text { Epelboin et al. } 2016 \text {, } \\
\text { Morris et al. } 2016 ; \\
\text { Epelboin et al. } 2018\end{array}$ \\
\hline $\begin{array}{l}\text { Significant national and European funding } \\
\text { endowment, European membership and } \\
\text { citizenship }\end{array}$ & $\begin{array}{l}\text { Political stability and funding opportu- } \\
\text { nities promote long-term and transver- } \\
\text { sal research activities }\end{array}$ & $\begin{array}{l}\text { Investissement } \\
\text { d'avenir grants (e.g., } \\
\text { Labex CEBA); Euro- } \\
\text { pean Regional De- } \\
\text { velopment Fund } \\
\text { Operational Pro- } \\
\text { gram; FP7 European } \\
\text { Commission "REG- } \\
\text { POT" }\end{array}$ \\
\hline
\end{tabular}


Table 2. Main categories of drivers for explaining global emergence and reemergence of human pathogens as used by Woolhouse and Gowtage-Sequeria (2005) and corresponding ranking of the same drivers for French Guiana based on a questionnaire sent to the different coauthors (replies=26) by the two lead authors of this review. This table is ranked from the most cited driver to the least by the coauthors for the French Guiana conditions.

\begin{tabular}{|l|l|l|}
\hline Drivers & Rank in W-GS (2005) & Rank for French Guiana ( \pm SD) \\
\hline $\begin{array}{l}\text { Changes in human demographics } \\
\text { and society }\end{array}$ & 2 & $1(2.36)$ \\
\hline $\begin{array}{l}\text { Changes in land use or agricultural } \\
\text { practices }\end{array}$ & 1 & $2(2.52)$ \\
\hline Poor population health & 3 & $3(2.03)$ \\
\hline International travel & 7 & $4(2.77)$ \\
\hline $\begin{array}{l}\text { Pathogen evolution and proper- } \\
\text { ties }\end{array}$ & 5 & $5(2.20)$ \\
\hline Failure of public health programs & 8 & $6(2.16)$ \\
\hline Climate change & 10 & $7(2.55)$ \\
\hline $\begin{array}{l}\text { Contamination of food sources or } \\
\text { water supplies }\end{array}$ & 6 & $8(1.91)$ \\
\hline International trade & 9 & $9(2.14)$ \\
\hline Hospitals and medical procedures & 4 & $10(1.57)$ \\
\hline
\end{tabular}

\section{Highlights}

- Both scientific and biomedical research tends to work in silos, what the OneHealth and Ecohealth concepts keep hammering.

- Zoonotic and vector-borne infectious diseases form an important group of diseases that are emerging and reemerging today in the World.

- Synthetizing near 15 years of research in French Guiana, South America on zoonotic and vector-borne infections reveals important new insights onto the wildlife-ecosystemdisease nexus.

- Important environmental, demographic and socio-economic changes in French Guiana interfere favoring the development of ancient and new infectious diseases. 

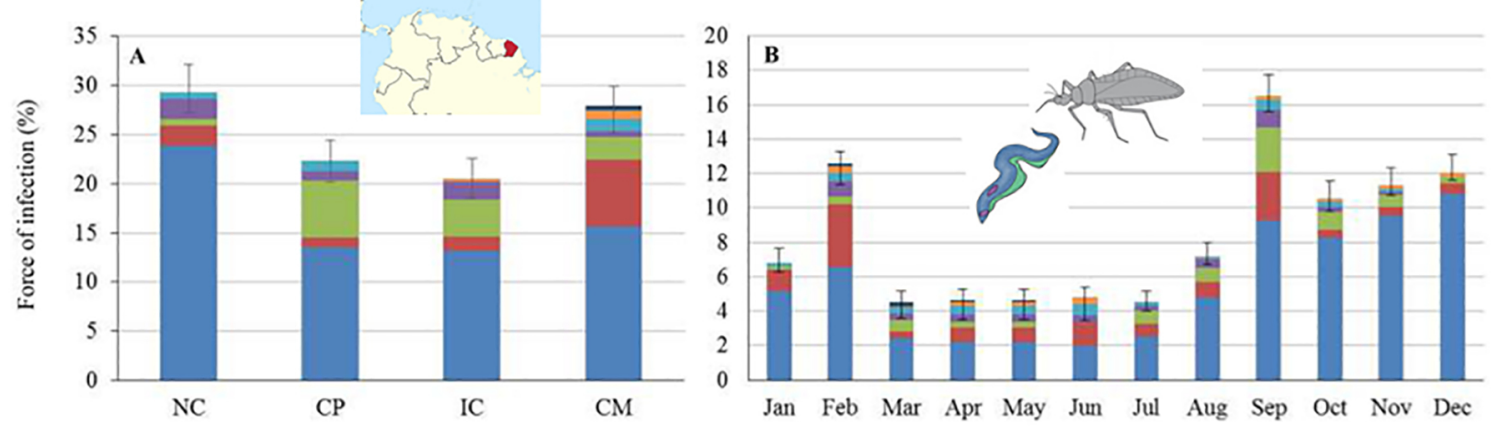

Figure 1 


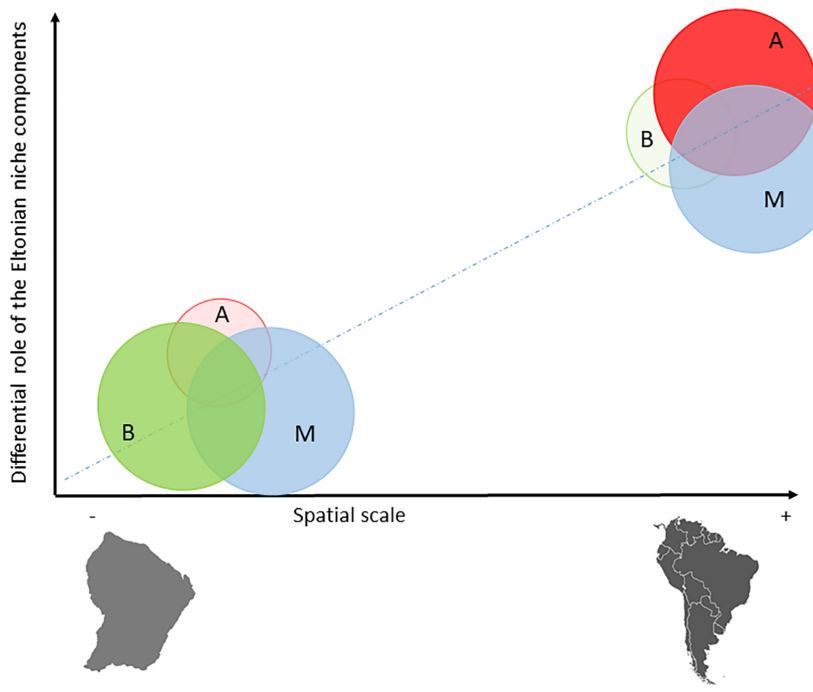

Figure 2 